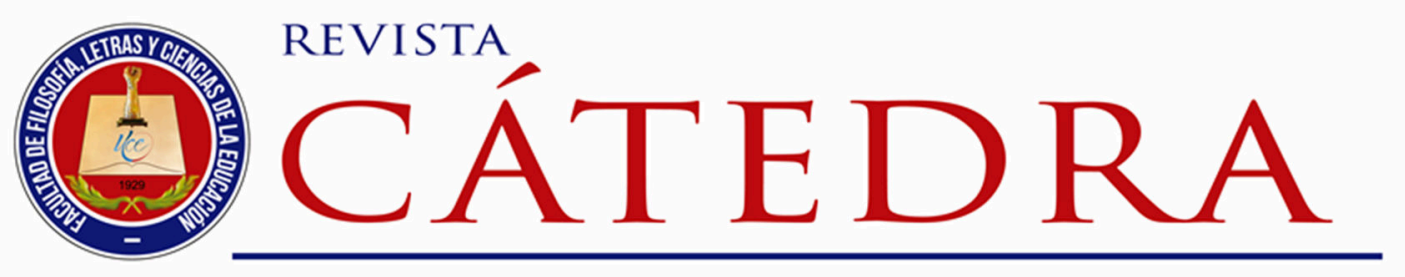

\title{
Consideraciones didácticas, tecnológicas y comunicacionales para el diseño de un entorno virtual de enseñanza aprendizaje
}

\author{
Didactic, technological and communicational \\ considerations for EVEA design
}

\author{
Jorge Santamaría-Muñoz \\ Universidad Central del Ecuador, Quito, Ecuador \\ jasantamaria@uce.edu.ec \\ https://orcid.org/0000-0001-8639-4300
}

(Recibido: 18/11/2021; Aceptado: 30/11/2021; Versión final recibida: 15/12/2021)

Cita del artículo: Santamaria-Muñoz, J. (2022). Consideraciones didácticas, tecnológicas y comunicacionales para el diseño de EVEA. Revista Cátedra, 5(1), 80-105.

\section{Resumen}

En la investigación determinamos los aspectos didácticos, pedagógicos, tecnológicos y metodologías de aprendizaje, que se consideran para desarrollar un Entorno Virtual de Enseñanza Aprendizaje (EVEA) a fin de garantizar un aprendizaje de calidad. Para ello utilizamos el enfoque cualitativo apoyado del diseño de la teoría fundamentada con el propósito de generar teorías, conceptos o hipótesis a partir del análisis de los puntos de vista de los entrevistados y el contraste con la literatura analizada previamente. En este sentido, entrevistamos a 8 expertos en la temática de diseño e implementación de EVEA y los datos obtenidos se analizaron mediante el software ATLAS.TI 8, siguiendo el modelo de la concepción emergente.

De acuerdo a los resultados obtenidos determinamos que para diseñar un EVEA se debe utilizar el modelo instruccional de Análisis, Diseño, Desarrollo, Implantación y Evaluación (ADDIE), los recursos del EVEA deben ser variados para atender a la diversidad de estilos de aprendizaje y sus contenidos deben ser actuales, las actividades deben estar enfocadas a resolver problemáticas del contexto profesional del estudiantado y deben fomentar el aprendizaje autónomo y colaborativo, se deben considerar los fundamentos andragógicos del estudiantado, y finalmente el uso del enfoque de aprendizaje híbrido (b-learning) y la metodología de la clase invertida (flipped classroom) de modo que utilicen las TIC como apoyo al proceso de enseñanza y aprendizaje, y se aproveche el tiempo de clase.

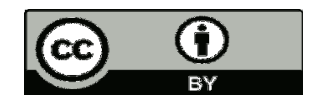


Palabras clave

entorno virtual de enseñanza aprendizaje, ADDIE, andragogía, Moodle, TIC.

\section{Abstract}

In this research we determined the didactic, pedagogical, technological aspects as well as the learning methodologies which should be considered in order to develop an VTLE that guarantees a quality learning. For this purpose, we used the qualitative approach supported by the design of the grounded theory with the purpose of generating theories, concepts or hypotheses from the analysis of the interviewees' points of view and the contrast with the literature previously analyzed. In this sense, we interviewed 8 experts in the subject of design and implementation of VTLE and the data obtained were analyzed by means of the software ATLAS.TI 8, following the model of the emergent conception.

According to the results obtained, we determined that in order to design a VTLE the instructional design ADDIE should be used, the resources of the VTLE should be varied to assist the diversity of learning styles and the contents should be up-to-date, the activities should be focused to solve problems of the professional context of the students and they should promote the autonomous and collaborative learning, the andragogical foundations of the students must be also considered, and finally the use of the B-Learning approach and the Flipped Classroom methodology so that they use ICT tools to support the teaching and learning processes.

\section{Keywords}

Virtual teaching and learning environment, ADDIE, andragogy, Moodle, ICT.

\section{Introducción}

Desde la llegada de internet hasta la actualidad su crecimiento ha sido masivo. En el año 2020 el 61\% de la población mundial tiene acceso a internet, y en Latinoamérica su penetración llega al 71\% de la población (Internet World Stats, 2020). Como consecuencia se ha producido un fácil acceso a gran cantidad de información y permitiendo una comunicación directa desde cualquier lugar del mundo.

En este sentido las instituciones educativas no pueden mantenerse al margen de su utilización, aislándose en prácticas educativas obsoletas y tradicionales. En el ámbito de la educación el internet ofrece varias posibilidades, al respecto Tesouru y Puiggalí (2004) refieren que permite: a) proporcionar información para fortalecer el conocimiento del estudiantado; b) proporcionar una gran variedad de herramientas (simuladores, juegos, videos, etc.) haciendo más amena la adquisición de conocimientos; c) proporcionar numerosas fuentes de información como bases de datos, buscadores académicos y artículos para la realización de trabajos investigativos; d) permitir el proceso de formación por medio de cursos que se encuentre en la red; e) brindar la posibilidad de que el proceso educativo no sea presencial debido a que facilita que el estudiantado pueda participar en el desarrollo del curso en cualquier lugar, y; d) romper con las barreras de distancia al facilitar la comunicación sincrónica y asincrónica con cualquier persona sin importar donde se encuentre. Como hemos observado la incorporación de las Tecnologías de la Información y Comunicación (en adelante TIC) en el ámbito educativo, han permitido tener una nueva visión de los escenarios donde se produce el proceso de enseñanza aprendizaje.

En este sentido, los Entornos Virtuales de Enseñanza Aprendizaje (en adelante EVEA), se convierten en una herramienta eficaz para favorecer los aspectos mencionados anteriormente. Debido a que facilitan el desarrollo del currículo mediante contenidos y actividades formativas, a más de fomentar la participación y comunicación entre sus actores 
(estudiantes y docentes) de forma síncrona y asíncrona, permiten la evaluación del estudiante y la optimización del proceso de enseñanza-aprendizaje en cualquier modalidad educativa presencial, en línea, a distancia o semipresencial (Colina y Gutiérrez, 2013; Belloch, 2010; Salmerón, Rodríguez, y Gutiérrez, 2010; Salinas, 2012).

Es evidente observar como en las últimas décadas la educación en línea ha obtenido un constante crecimiento. Estudios de Online Business School (OBS, 2014) afirman que, en el año 2019, cerca del 50\% de la enseñanza superior del mundo se impartió a través del ELearning. Además, de acuerdo al informe 'Momento decisivo: La educación superior en América Latina y el Caribe', publicado por el Banco Mundial, la formación por internet ha crecido un $900 \%$ a nivel mundial (BM, 2017).

Sin embargo, a nivel de Latinoamérica la situación es alarmante. La Organización para la Cooperación y el Desarrollo Económicos (OECD, 2015) en sus estudios determinó que en Latinoamérica solo el $19 \%$ de las instituciones de educación se centran en la educación a distancia o educación virtual. Basándonos en nuestro contexto de acuerdo a datos obtenidos del portal "Oferta vigente del Sistema de Educación Superior" del Consejo de Educación Superior (CES, 2020) de las 60 universidades y escuelas politécnicas que existen en Ecuador, solo 10 de ellas, es decir el 16,66\% ofertan programas de maestrías profesionales y especializaciones no médicas bajo la modalidad en línea. Y de las 60 universidades y escuelas politécnicas que existen en Ecuador solo 17 de ellas es decir el 28,33\% ofertan carreras de tercer nivel bajo la modalidad en línea. Conscientes de esta problemática en la investigación se determinó los aspectos didácticos, tecnológicos y comunicacionales que son adecuados para el diseño de un EVEA, así como también los diseños instruccionales para el levantamiento de las plataformas virtuales que permita garantizar un aprendizaje de calidad, para proyectarse en la educación virtual.

La investigación se encuentra estructurada de la siguiente manera: en la sección 2, se hace constar la revisión de la literatura y fundamentación teórica relacionada con los aspectos a considerar para el diseño de EVEA; en la sección 3, se describe el enfoque, alcance y diseño de la investigación, así como la población y muestra, técnicas e instrumentos para la recolección de datos y la forma en las que fueron analizados; en la sección 4, presentamos el análisis e interpretación de los resultados obtenidos a partir de las entrevistas aplicadas a expertos diferencias de las áreas; en la sección 5, se realizó la discusión de los resultados mediante el contraste con autores referentes a la temática de la investigación, finalmente en la sección6, se describen las conclusiones derivadas del proceso de investigación.

\section{Revisión de la literatura}

\subsection{Entornos virtuales de enseñanza aprendizaje (EVEA)}

Paz-Florio (2015) menciona que un EVEA "son plataformas informáticas cuyo propósito es orientar la comunicación pedagógica entre los participantes que intervienen en el proceso educativo y crear espacios o comunidades organizadas en torno al aprendizaje" (p.1). En este sentido, un EVEA es un espacio virtual diseñado para complementar y fortalecer el proceso de enseñanza aprendizaje por medio de la integración de actividades (autónomas y colaborativas) y recursos interactivos desarrollados a través de distintas herramientas tecnológicas de la web 2.0 y 3.0. En las características más importantes del EVEA tenemos:

- Proporcionar a los participantes un fácil acceso a recursos y actividades de aprendizaje.

- Permitir una mayor flexibilidad para realizar las actividades de aprendizaje.

- Facilitar la comunicación entre: docentes-estudiantes y estudiantes-estudiantes por medio de herramientas de comunicación sincrónica y asincrónica. 


\subsection{Aspectos didácticos para el diseño de un EVEA}

\subsubsection{Diseño instruccional}

Belloch (2013) refiere a que el "diseño instruccional está enfocado en crear un ambiente de aprendizaje y los materiales, claros y efectivos, que ayudarán al estudiante a desarrollar la capacidad de resolver tareas específicas" (p.5). En este sentido, establecemos que el diseño instruccional se refiere a un esquema el cual involucra los procesos inmersos en el diseño, implementación y evaluación de un ambiente de aprendizaje con el objetivo de planificar el proceso de formación, seleccionar las herramientas más apropiadas y aún más importante adaptar las actividades y recursos a las necesidades del estudiantado al que se dirige el curso.

\subsubsection{Modelos del diseño instruccional}

Para Belloch (2013) "los Modelos de Diseño Instruccional sirven de guía a los profesionales, sistematizando el proceso de desarrollo de acciones formativas" (p.2). Así, el modelo del diseño instruccional contiene la descripción de las reglas, roles, y recursos que se usarán para el desarrollo de ambientes de aprendizaje.

Existen varios modelos de diseño instruccional, tales como el modelo de Gagné y Briggs, modelo de Dick y Care, modelo ASSURE, modelo ADDIE, etc., sin embargo para el desarrollo de la investigación se optó por modelo instruccional ADDIE debido a que presenta mayor flexibilidad para en el desarrollo de entornos educativos de calidad a nivel universitario, y en los últimos años se ha utilizado en la Facultad de Filosofía, Letras y Ciencias de la Educación de la Universidad Central del Ecuador, lugar donde se realizó la investigación.

\subsubsection{Modelo instruccional ADDIE}

El modelo instruccional ADDIE es un modelo que sirve como referencia para el desarrollo de ambientes de aprendizaje su nombre es un acrónimo de sus fases las cuales son Análisis, Diseño, Desarrollo, Implementación y Evaluación; y su objetivo es guiar al estudiante a la construcción del conocimiento en un espacio de aprendizaje.

Para Castillo (2009) las fases del modelo ADDIE están basadas en una "metodología sistémica, eficiente y efectiva para la producción de recursos educativos. La fuerza que ha tomado el Modelo ADDIE en los últimos años proviene de que se asume que es un modelo genérico" (p.4). A continuación, se describe de manera detallada cada una de sus fases:

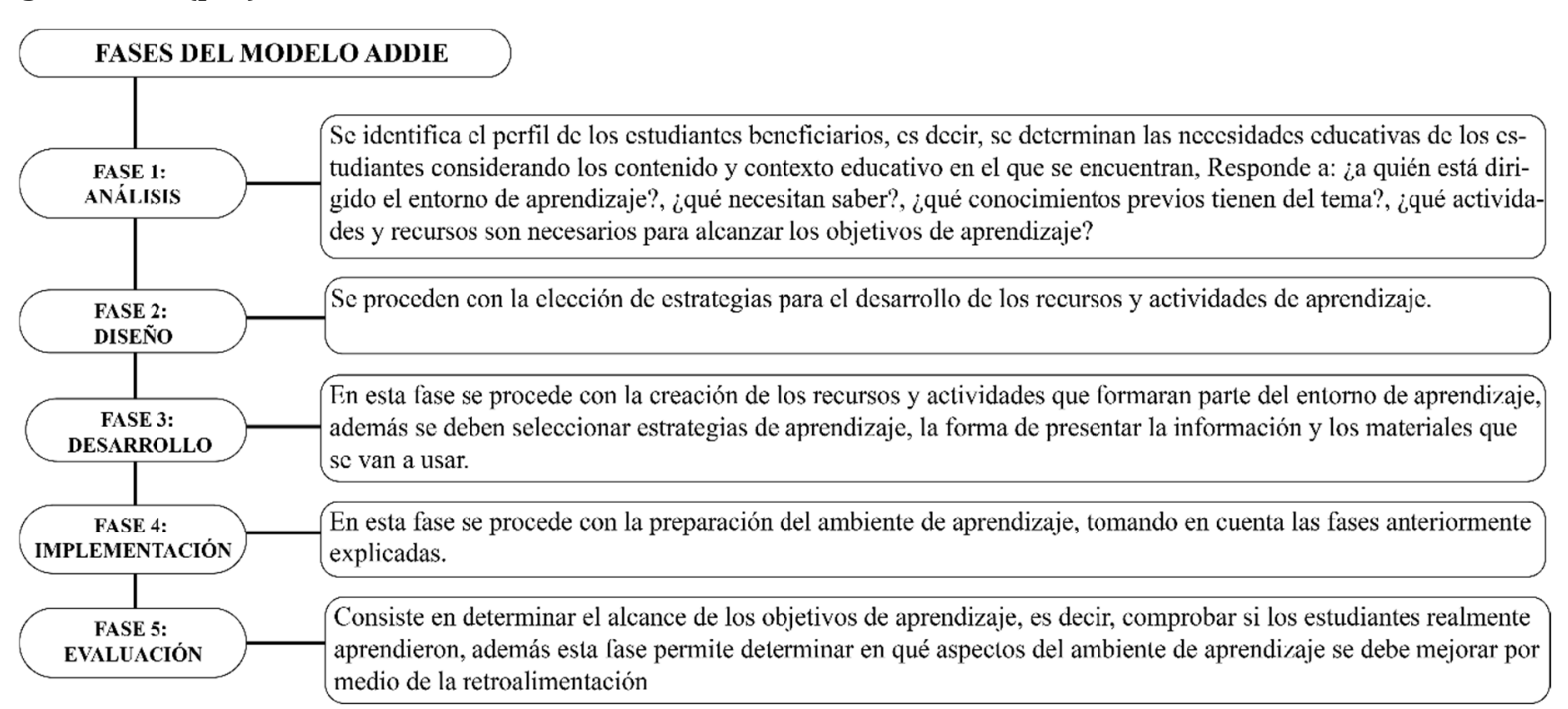

Figura 1. Fases del Modelo ADDIE

\subsubsection{Diseño de actividades digitales}


Las actividades de aprendizaje en línea ubican al estudiante en un rol mucho más activo que las actividades de aprendizaje convencionales, donde el estudiante juega un papel protagónico y su participación es la clave del éxito en su proceso de aprendizaje. Cabero y Román (2006) hacen referencia a que las actividades de aprendizaje deben ayudar al estudiante a comprender, analizar, sintetizar y valorar los contenidos propuestos con el objetivo de convertir la información en bruto en un conjunto de conocimientos, habilidades y actitudes relativas a la asignatura trabajada. Es por ello que el diseño y selección de actividades es una de las tareas más importantes y deben responder a las preguntas tales como: ¿Qué actividades son más significativas?, ¿Qué actividades son más usuales o importantes de acuerdo a la temática del curso?, ¿A través de qué actividades se pueden desarrollar las diferentes capacidades de los estudiantes?, ¿Qué actividades se adecuan mejor a las características de los estudiantes? y ¿Qué actividades son más motivadoras?

En este sentido, una forma de clasificar las actividades es el uso de la Taxonomía de Bloom donde se clasifican a las actividades por conocimiento, comprensión, aplicación, análisis, síntesis y evaluación. Finalmente, entre los aspectos que se deben considerar para el diseño de actividades Cabero y Román (2006) establece que se debe:

a) especificar con claridad el contexto y el entorno donde se realizará la actividad; b) determinar los límites temporales para su realización y entrega; c) determinar la forma en que será enviada; d) explicar los recursos que podrán usar los estudiantes para su realización; e) establecer el número de estudiantes que pueden realizar la actividad, así como su modalidad de participación; f) explicar que conductas se consideran deseables para el desarrollo de la actividad; g) establecer claramente los criterios para valorar la ejecución de la actividad, y; h) establecer como se presentará el producto final (escritura, tipo de material, extensión, etc.) (p.40).

\subsubsection{Diseño de recursos educativos digitales}

El uso de EVEA en contexto educativo ha cobrado mucha fuerza en los últimos años, se hace necesario por lo tanto la creación, búsqueda y selección de recursos educativos de calidad acordes a la demanda y a la oferta académica en sus distintas modalidades y que respondan a estándares de calidad previamente definidos. Así, para que un recurso sea de calidad se deben cumplir las condiciones siguientes: a) el creador de recursos debe tener un conocimiento muy amplio del tema; b) se deben establecer objetivos de enseñanzaaprendizaje con el propósito de delimitar contenidos; c) se debe elegir un recurso TIC para presentar el recurso; d) se deben plantear procedimientos metodológicos que permitirán al estudiante acercarse al objeto de estudio, y; e) los recursos digitales educativos de acuerdo al nivel de desarrollo cognitivo deseado a saber (Zapara, 2012). Refiriéndonos al literal e) es conveniente que:

- Para la formación de conceptos: se deben utilizar recursos que permitan al estudiante explorar información con el propósito de ampliar y adquirir conocimientos sobre un tema de estudio.

- Para la comprensión, asociación y consolidación de los aprendizajes: es importante utilizar recursos que permitan interactuar con el objetivo de comprender procesos e integrar el conocimiento. 


\subsection{Aspectos tecnológicos para el diseño de un EVEA}

\subsubsection{Herramientas TIC para el desarrollo de actividades y recursos propios de los EVEA con Moodle}

Herramientas TIC para desarrollar actividades de aprendizaje con Moodle: a continuación, describimos las herramientas que integra la plataforma Moodle para el desarrollo de actividades y su uso dentro de un EVEA:

\begin{tabular}{|c|c|c|}
\hline Actividad & Definición & Uso \\
\hline Chat & $\begin{array}{l}\text { - El foro es un espacio virtual } \\
\text { para la interacción social y } \\
\text { académica en el cual se puede } \\
\text { argumentar e introducir } \\
\text { interpretaciones de algún } \\
\text { tema en específico. }\end{array}$ & 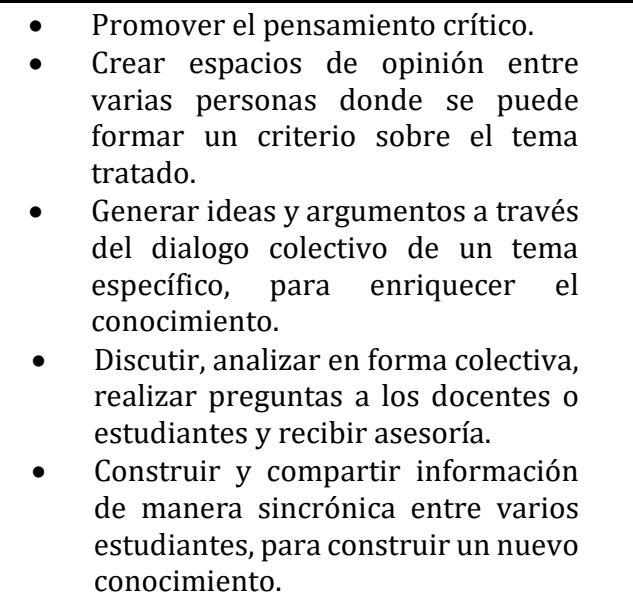 \\
\hline Videoconferencia & $\begin{array}{l}\text { - Herramienta } \\
\text { comunicación que permite la } \\
\text { comunicación sincrónica } \\
\text { entre el docente y los } \\
\text { estudiantes. }\end{array}$ & 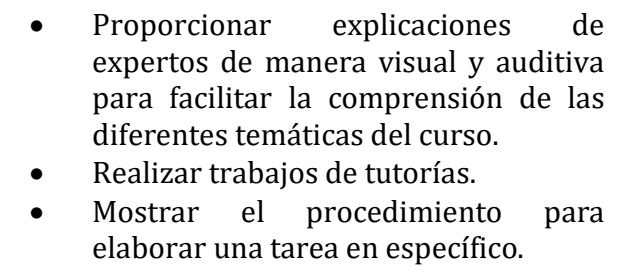 \\
\hline Tarea & $\begin{array}{l}\text { Herramienta que permite } \\
\text { planificar, organizar, calificar } \\
\text { evidencias solicitadas para el } \\
\text { desarrollo de una actividad. }\end{array}$ & $\begin{array}{l}\text { - Practicar y reforzar temáticas } \\
\text { aprendidas por los estudiantes. } \\
\text { - Construcción de conocimientos ya sea de } \\
\text { forma autónoma o cooperativa. } \\
\text { - Demostrar los conocimientos } \\
\text { desarrollados durante el proceso de } \\
\text { aprendizaje. }\end{array}$ \\
\hline Cuestionario & $\begin{array}{l}\text { - Herramienta de evaluación } \\
\text { que permite diseñar } \\
\text { cuestionarios de forma muy } \\
\text { sencilla y flexible. }\end{array}$ & $\begin{array}{l}\text { - Evaluar con el objetivo de determinar } \\
\text { debilidades y fortalezas de los } \\
\text { conocimientos respecto a un } \\
\text { determinado tema en el proceso de } \\
\text { aprendizaje. } \\
\text { Determinar que contenidos necesitan } \\
\text { una retroalimentación. }\end{array}$ \\
\hline Wiki & $\begin{array}{l}\text { - Es un sitio web que permite } \\
\text { la construcción r del } \\
\text { conocimiento de forma } \\
\text { colectiva con otros usuarios. }\end{array}$ & $\begin{array}{l}\text { - Fortalecer la comunicación y } \\
\text { colaboración del grupo. } \\
\text { - Construir conocimientos de manera } \\
\text { colectiva. }\end{array}$ \\
\hline
\end{tabular}




\subsubsection{Herramientas TIC para desarrollar recursos con Moodle:}

A continuación, se describen las herramientas que integra la plataforma Moodle para el desarrollo de recursos:

\begin{tabular}{|c|c|c|c|}
\hline Recuso & Definición & Uso & \\
\hline Archivo & $\begin{array}{l}\text { - Recurso que permite } \\
\text { adjuntar documentos de tipo } \\
\text { texto, imágenes, videos y } \\
\text { audios. }\end{array}$ & $\bullet$ & $\begin{array}{l}\text { Compartir material de apoyo o de } \\
\text { estudio. }\end{array}$ \\
\hline Carpeta & $\begin{array}{l}\text { - Herramienta que permite } \\
\text { alojar distintos tipos de } \\
\text { archivos. }\end{array}$ & & $\begin{array}{l}\text { Organizar la información de un tema } \\
\text { en específico } \\
\text { Compartir diferentes tipos de } \\
\text { recursos de manera organizada. } \\
\text { Crear un portafolio de evidencias. }\end{array}$ \\
\hline Url & $\begin{array}{l}\text { - Herramienta que permite } \\
\text { enlazar sitios web internos o } \\
\text { externos. }\end{array}$ & & $\begin{array}{l}\text { Proporcionar enlaces de interés } \\
\text { externos. } \\
\text { Enlazar recursos que se encuentran } \\
\text { dentro del EVEA. }\end{array}$ \\
\hline Libro & $\begin{array}{l}\text { - Recurso que permite } \\
\text { presentar temas a manera de } \\
\text { libro, es decir por capitos o } \\
\text { subcapítulos. }\end{array}$ & $\bullet$ & $\begin{array}{l}\text { Presentar material de lectura o de } \\
\text { estudio } \\
\text { Crear un portafolio de evidencias. }\end{array}$ \\
\hline Página & $\begin{array}{l}\text { - Recurso que permite insertar } \\
\text { páginas web dentro del } \\
\text { EVEA. }\end{array}$ & & $\begin{array}{l}\text { Elaborar recursos de aprendizaje } \\
\text { personalizados } \\
\text { Brindar orientaciones de actividades. }\end{array}$ \\
\hline Etiqueta & 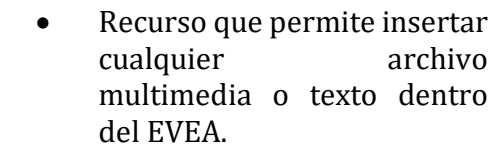 & & $\begin{array}{l}\text { Insertar recursos multimedia } \\
\text { personalizados. }\end{array}$ \\
\hline
\end{tabular}

Cuadro 2. Recursos en Moodle.

\subsection{Aprendizaje autónomo}

Se entiende por aprendizaje autónomo a la facultad que permite al estudiante regular su propio aprendizaje por medio de la toma de decisiones acertadas (Monereo y Castelló, 1997).

Crispín (2011) se refiere al aprendizaje autónomo como un proceso donde una persona autorregula su aprendizaje y toma conciencia de sus procesos cognitivos y socio-afectivos. De las definiciones anteriores determinamos que, en el aprendizaje autónomo el estudiante establece su propio ritmo de aprendizaje por medio de la apropiación de estrategias de aprendizaje que le permitan articular el conocimiento.

\subsection{Aprendizaje colaborativo}

Gunawardena, Lowe y Anderson (1997) refieren que el aprendizaje colaborativo como un proceso en el que cada persona aprende más de lo que aprendería por sí sola, por medio de la interacción con los integrantes del grupo. Así podemos entender al aprendizaje colaborativo como un proceso donde el estudiante genera una construcción más eficiente del conocimiento mediante la interacción con su grupo de trabajo, el contraste de cada punto de vista de sus integrantes y la cooperación de sus miembros.

Es importante mencionar que en el aprendizaje "los sujetos trabajan juntos", siendo posible la división espontánea del trabajo, además de que la participación es horizontal y los roles Licencia Creative Commons Atribución 4.0 Internacional (CC BY 4.0) 
pueden cambiar permanentemente, a diferencia de la cooperación, donde la división del trabajo es "vertical" y "fija" (SUMMA, 2019). El aprendizaje colaborativo se crea cuando existe una interdependencia entre los integrantes del grupo bien definida. Johnson y Johnson (1999) refiere a que algunos de los principios para que se del aprendizaje colaborativo son: la colaboración, la responsabilidad, la comunicación, el trabajo en equipo y la autoevaluación. A continuación, detallamos cada una de las fases de acuerdo al autor anteriormente señalado:

- La colaboración: apoyo entre los integrantes del grupo para adquirir conocimientos de la temática de estudio, en esta etapa se comparten todos los recursos, logros y metas.

- La responsabilidad: cada integrante del grupo debe ser responsable del porcentaje de trabajo asignado. Y todos los integrantes deben permanecer involucrados en la tarea de cada integrante para apoyarse en momentos de dificultad.

- La comunicación: consiste en compartir información relevante, apoyarse de forma eficiente, retroalimentarse para optimizar el trabajo y analizar las conclusiones de cada integrante con el propósito de obtener resultados de mejor calidad.

- El trabajo en equipo: consiste en resolver juntos las problemáticas, desarrollando capacidades de organización, planificación, comunicación, liderazgo y resolución de problemas.

- La autoevaluación: cada integrante del grupo evalúa su desempeño de manera individual y colectiva, con la finalidad rectificar errores y mejorar las dinámicas de trabajo.

\subsection{Andragogía, características del estudiante adulto}

A lo largo de su trayectoria profesional Knowles (1975, 1978, 1980, 1984, 1989, 1990) planteó 6 principios andragógicos, este sentido tenemos:

- La necesidad de saber: En este principio se parte del supuesto de que el adulto necesita conocer porque debe aprender algo antes de emprender el aprendizaje y usarlo en su vida real, es por ello que el estudiantado adulto necesita información referente a cómo va a llevar a cabo el aprendizaje, qué va a aprender y por qué es importante dicho aprendizaje. Al respecto, Tough (1971) refiere que cuando un estudiante decide aprender por sí mismo, indaga sobre los beneficios que pueden obtener de dicho aprendizaje y las consecuencias negativas de no adquirirlo. En este sentido, el docente debe concientizar al estudiantado la necesidad de saber, para que por sí mismo acceda al conocimiento de manera oportuna y se produzca un aprendizaje significativo.

- El autoconcepto: Es importante tomar en cuenta que el estudiante adulto tiene el autoconcepto de ser responsable de sus propias decisiones, de ser una persona autodirigida y autónoma. A medida que una persona madura, su autoconcepto pasa de ser una persona dependiente a ser un ser humano autodirigido. Knowles y Kolb (2005) hace énfasis a que el docente debe identificar, orientar y respetar las decisiones sobre el nivel de autonomía del estudiante adulto. Considerando estas características es importante que el docente evite crear situaciones que causen que el estudiante adulto sienta que le están tratando de imponer u ordenar, debido a que podría causar molestias o resistencia.

- El papel de la experiencia: Se debe considerar que el estudiantado adulto llega a la actividad educativa con un alto nivel de experiencia, necesidades, intereses y objetivos, es por ello que se debe hacer énfasis a la enseñanza individualizada. Así, Sánchez (2015) en su tesis doctoral titulada "La Andragogía de Malcom Knowles: Teoría y Tecnología de la Educación de Adultos" menciona que: "algunas de las técnicas que aprovechan la experiencia del alumno adulto son los grupos de 
discusión, los ejercicios de simulación, la resolución de problemas, el estudio de casos, los métodos de laboratorio y las actividades de ayuda entre pares" (p.97).

- La disposición para aprender: En este principio se asume que los estudiantes adultos están preparados para aprender lo que necesitan para hacer frente a las situaciones de su vida cotidiana. Knowles (1980) refiere que es posible que esta disposición no se dé de manera natural por lo que recomienda usar estrategias como la orientación profesional o ejercicios de simulación. Tomar en cuenta los aspectos señalados permitirán desarrollar al estudiante la disposición hacia el aprendizaje.

- La orientación al aprendizaje: A diferencia de la pedagogía donde el aprendizaje se centra en la acumulación de contenidos para ser promovido de nivel en la andragogía la orientación del aprendizaje está centrada en la vida, tarea o problema. Los adultos están motivados al proceso de aprendizaje cuando perciben que les ayudará a realizar tareas o hacer frente a problemas que se le presentan de su contexto, por esta razón aprenden de manera más efectiva cuando los conocimientos se presentan en el contexto de aplicación de situaciones de la vida cotidiana. Knowles (1980) refiere que no tomar en cuenta esta característica ha sido la principal causa de abandono de los estudiantes adultos en cursos de alfabetización como en cursos universitarios. Es por ello que es docente debe orientar el proceso de aprendizaje a situaciones del contexto del estudiantado.

- La motivación. Si bien los estudiantes adultos responden a motivadores externos tales como: mejores trabajos, aumentos salariares, promociones, etc., Knowles (1980) refiere que los motivadores más eficiente son las presiones internas como, por ejemplo: aumentar su satisfacción laboral, calidad de vida, autoestima, etc.

\subsection{Estilos del aprendizaje}

Existen varios modelos y teorías sobre los estilos de aprendizaje, aun cuando estas tienen una clasificación distinta, tienen similitudes en común que permiten entender los comportamientos de los individuos y como se relacionan en la forma en que aprenden con el propósito de determinar qué acción puede ser más eficaz en cada momento dado.

A continuación, se describe el modelo que se utilizó en la investigación:

\subsubsection{Modelo de la programación neurolingüística de Bandler y Grinder}

En este modelo se hace referencia a la forma en el que el estudiante comprende la información por medio de los sentidos. Bandler y Grinder (1982) llamaron también a este modelo como visual-auditivo-kinestésico, haciendo referencia a que la información se puede representar de manera visual, auditiva y kinestésica. A continuación, se describen cada una de las características de los sistemas propuestos por los autores:

- Sistema de representación visual: los estudiantes que se ubican en esta categoría, aprenden mejor cuando la información se representa de manera visual. El sistema de representación visual facilita al estudiante absorber grandes cantidades de información con rapidez.

- Sistema de representación auditivo: los estudiantes que forman parte de este sistema recuerdan la información de manera secuencial u ordenada, aprenden mejor cuando reciben explicaciones de manera oral y cuando tienen la oportunidad de explicar la información a otra persona. El sistema auditivo a diferencia del sistema visual no permite relación o elaborar conceptos abstractos con facilidad, sin embargo, es fundamental para el aprendizaje de los idiomas o música.

- Sistema de representación kinestésico: este sistema se refiere a la capacidad de los individuos para procesar a información asociándola a sus sensaciones o movimientos, se utiliza con mayor frecuencia cuando se aprende un deporte, este sistema es más lento que el sistema visual y auditivo, los estudiantes que se ubican 
en este sistema necesitan más tiempo que los demás, debido a que aprenden de manera distinta. Los estudiantes de este sistema aprenden de mejor manera cuando se involucran en experimentos de laboratorio o proyectos.

Además, los autores anteriormente señalados mencionan que un 40\% de los individuos usan el sistema visual, el 30\% auditivo y un $30 \%$ kinestésico.

\subsection{Metodologías de aprendizaje activas para la virtualidad}

\subsubsection{Flipped Learning}

Existen confusiones entre los términos Flipped Classrom y Flipped Learning, por lo que es importante mencionar que, en el 2014 la Flipped Learning Network de ahora (en adelante FLN), la cual es una red de aprendizaje dedicada a proporcionar conocimientos, habilidades y recursos para su implementación, modificó el termino Flipped Classrom (aula invertida) a Flipped Learning (aprendizaje invertido). FLN (2014) menciona que, aunque ambos términos son correctos, sin embargo, el segundo es más completo debido a que al invertir una clase no necesariamente se invierte el aprendizaje. En este sentido, se define al aprendizaje invertido como:

Un enfoque pedagógico en el que la instrucción directa se desplaza de la dimensión del aprendizaje grupal a la dimensión del aprendizaje individual, transformándose el espacio grupal restante en un ambiente de aprendizaje dinámico e interactivo en el que el facilitador guía a los estudiantes en la aplicación de los conceptos y en su involucramiento creativo con el contenido del curso (FLN, 2014, p.1).

De acuerdo a las consideraciones anteriormente mencionadas, establecemos que el Flipped Learning es un modelo pedagógico donde se invierte la clase tradicional, a una clase que involucre el aprendizaje activo de los estudiantes, permitiendo que la exposición se centre al estudiante y no al docente, a partir de la información transmitida por el docente previamente a través de recursos tecnológicos revisados por los estudiantes fuera del aula.

\section{Métodos y materiales}

\subsection{Enfoque}

La investigación se basó en el enfoque cualitativo. Al respecto Sampieri et al. (2014) afirma que la investigación cualitativa se fundamenta en una perspectiva interpretativa centrada en el entendimiento sus participantes.

\subsection{Alcance}

La investigación tuvo un alcance descriptivo debido a que realizamos una descripción de los aspectos didácticos-pedagógicos, tecnológicos y metodológicos que se requieren para desarrollar un EVEA, de acuerdo con Monje-Álvarez (2011) este alcance permite:

Reunir los resultados de la observación en una exposición de los rasgos del fenómeno que se estudia, de acuerdo con criterios que le den coherencia y orden a la presentación de los datos, a fin de llegar a la formulación de hipótesis. En el nivel descriptivo no se plantean hipótesis, la finalidad de la etapa descriptiva es la de generalizar a fin de llegar a la formulación de hipótesis (p. 95).

\subsection{Diseño}

La investigación se basó en el diseño de la teoría fundamentada, sobre este diseño Sampieri et al., (2014) afirma que mediante su aplicación el investigador produce una explicación general o teoría respecto a un fenómeno, proceso, acción o interacciones que se aplican a un contexto concreto desde la perspectiva de participantes, para desarrollar hipótesis y variables o conceptos que la integran mediante una representación o modelo visual, que posteriormente será contrastado con la literatura analizada previamente. 


\subsection{Población y muestra}

En la investigación utilizamos la "muestra de expertos", con el propósito de generar hipótesis más precisas. En lo que respecta al tamaño de la muestra Sampieri et al (2014) afirma:

No hay parámetros definidos ni precisos, por cuanto la decisión del número de casos que conformen la muestra es del investigador, siempre y cuando tome en cuenta los factores siguientes:

- Capacidad operativa de recolección y análisis (el número de casos que podemos manejar de manera realista y de acuerdo con los recursos que tenemos).

- El entendimiento del fenómeno (el número de casos que nos permitan responder a las preguntas de investigación, que más adelante se denominará "saturación de categorías").

- La naturaleza del fenómeno en análisis (si los casos o unidades son frecuentes y accesibles o no, si recolectar la información correspondiente lleva poco o mucho tiempo) (p.384).

Tomando en cuenta los aspectos señalados anteriormente la muestra de la investigación se conformó por 8 expertos en la temática de diseño e implementación de EVEA, de la manera siguiente:

\begin{tabular}{|c|c|c|}
\hline Entrevistados & $\begin{array}{l}\text { Años de experiencia en } \\
\text { construcción de EVEA }\end{array}$ & Función \\
\hline Experto 1 & 15 años & $\begin{array}{l}\text { PhD. En Ciencias de la } \\
\text { Computación. } \\
\text { Docente UCE. } \\
\text { Docente PUCE. }\end{array}$ \\
\hline Experto 2 & 10 años & $\begin{array}{l}\text { Magister en Educación Superior. } \\
\text { Doctorado en Educación. } \\
\text { Docente UCE. }\end{array}$ \\
\hline Experto 3 & 5 años & $\begin{array}{l}\text { PhD. en Investigación Educativa. } \\
\text { Docente UCE. } \\
\text { Director de la Carrera de } \\
\text { Pedagogía de las Ciencias } \\
\text { Experimentales Informática. }\end{array}$ \\
\hline Experto 4 & 10 años & $\begin{array}{l}\text { Magister en Nuevas Tecnologías } \\
\text { Aplicadas a la Educación. } \\
\text { Especialización en Entornos } \\
\text { virtuales de aprendizaje. } \\
\text { Docente UCE. }\end{array}$ \\
\hline Experto 5 & 7 años & $\begin{array}{l}\text { Master en sistemas } \\
\text { Docente UCE. }\end{array}$ \\
\hline Experto 6 & 6 años & $\begin{array}{l}\text { Magister en Sistemas } \\
\text { Informáticos } \\
\text { Educativos. } \\
\text { Docente UCE. }\end{array}$ \\
\hline Experto 7 & 7 años & $\begin{array}{l}\text { Diseñador Instruccional. } \\
\text { Dirección de desarrollo } \\
\text { académico UCE. }\end{array}$ \\
\hline Experto 8 & 5 años & $\begin{array}{l}\text { Diseñador instruccional. } \\
\text { Docente. }\end{array}$ \\
\hline
\end{tabular}

Cuadro 3. Docentes expertos entrevistados 


\subsection{Técnicas e instrumentos de investigación}

La técnica que se utilizó para la recolección de datos fue la "entrevista cualitativa" la cual se según Sampieri et al., 2014 se define "como una reunión para conversar e intercambiar información entre una persona (el entrevistador) y otra (el entrevistado) u otras (entrevistados)" (p. 403). Además, el tipo de entrevista que seleccionamos para la investigación fue de tipo semiestructurada con el propósito de ofrecer a los entrevistados una guía de preguntas, y que el investigador tenga la libertad de introducir preguntas adicionales para aclarar conceptos u obtener mayor información. Finalmente, para la elección de los tipos de preguntas de la entrevista utilizamos la clasificación de Mertens (2010) y de dicha clasificación seleccionamos preguntas de conocimiento y de opinión.

\subsection{Validez de los instrumentos}

La validación del instrumento se realizó por medio del juicio de tres expertos especialistas en la temática propuesta (construcción de EVEA).

\subsection{Criterio de dependencia}

En la investigación cualitativa la dependencia también denominada consistencia lógica representa a la "confiabilidad cuantitativa", y se refiere a que los datos recolectados sean revisados por distintos investigadores y sus interpretaciones deben ser congruentes es decir general resultados equivalentes (Sampieri et al., 2014).

En este sentido, para garantizar que la investigación cumpla con el criterio de dependencia se recurrió al análisis de las entrevistas por parte de dos expertos en la temática, de modo que las categorías obtenidas a partir del análisis fueron equivalentes como se muestra a continuación:

\begin{tabular}{|c|c|c|}
\hline \multicolumn{2}{|c|}{ Categorías experto 1} & \multirow{2}{*}{$\begin{array}{l}\text { Categorías experto } 2 \\
\text { Importancia del diseño instruccional en los EVEA }\end{array}$} \\
\hline 1. & $\begin{array}{l}\text { Consideraciones para seleccionar un diseño } \\
\text { instruccional para la construcción de EVEA }\end{array}$ & \\
\hline 2. & $\begin{array}{l}\text { Criterios didácticos para elaborar recursos y } \\
\text { actividades educativas virtuales }\end{array}$ & $\begin{array}{l}\text { Diseño de actividades educativas virtuales } \\
\text { Diseño de recursos educativos virtuales }\end{array}$ \\
\hline 3. & $\begin{array}{l}\text { Herramientas TIC para la construcción de } \\
\text { actividades y recursos en EVEA }\end{array}$ & Herramientas TIC para el apoyo al aprendizaje \\
\hline 4. & $\begin{array}{l}\text { Elementos a considerar para diseñar la } \\
\text { interfaz de un EVEA }\end{array}$ & Interfaz de navegación del EVEA \\
\hline 5. & Rol del docente para el estudiantado adulto & Características del estudiantado adulto \\
\hline 6. & $\begin{array}{l}\text { Estrategias para atender a estilos de } \\
\text { aprendizaje }\end{array}$ & Estilos de aprendizaje \\
\hline 7. & Aprendizaje autónomo & Aprendizaje autónomo \\
\hline 8. & Aprendizaje colaborativo & Aprendizaje colaborativo \\
\hline 9. & $\begin{array}{l}\text { Consideraciones para seleccionar } \\
\text { metodologías de aprendizaje activas en EVEA }\end{array}$ & $\begin{array}{l}\text { Selección de metodologías de aprendizaje activas } \\
\text { en EVEA }\end{array}$ \\
\hline \multicolumn{3}{|c|}{ Cuadro 4. Criterio de dependencia de las entrevistas } \\
\hline \multicolumn{3}{|c|}{$\begin{array}{l}\text { 3.8. Técnicas de procesamiento de datos } \\
\text { Para el procesamiento de los datos utilizamos el Software ATLAS.TI 8, debido a este } \\
\text { software nos permitió la realización de la codificación en primer plano (codificación } \\
\text { abierta para formar categorías) y la codificación en segundo plano (codificación axial) de } \\
\text { los datos obtenidos en las entrevistas y construir teoría mediante la relación de conceptos } \\
\text { teorías y temas. }\end{array}$} \\
\hline
\end{tabular}

\subsection{Técnicas de análisis de datos}

Tomando en cuenta que para el desarrollo de la investigación nos basamos en el enfoque cualitativo y en el diseño de la teoría fundamentada, los pasos que seguimos para el análisis 
de datos fueron los de la concepción emergente. Sampieri et al. (2014) afirma que, en este diseño, el análisis de datos se efectúa por medio de la codificación abierta para generar categorías, las cuales se conectan entre sí para producir teoría, y cual se representa de manera gráfica para luego ser contrastada con la literatura previamente analizada. A continuación, describimos de manera gráfica el proceso que siguió la investigación para el análisis de los datos recolectados:

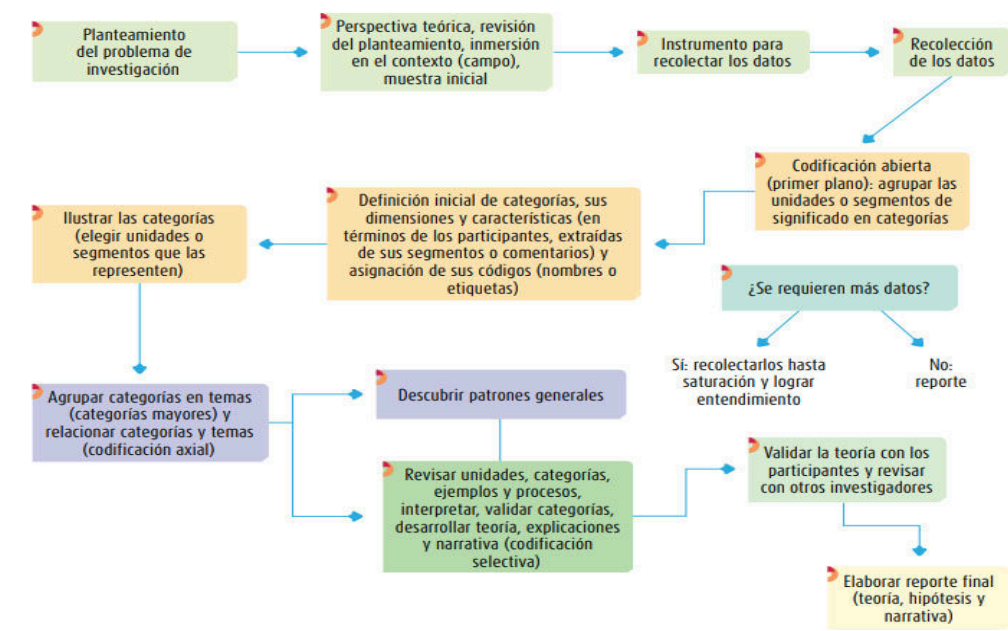

Figura 2. Proceso de la Investigación Cualitativa Basada en el Diseño de la Teoría Fundamentada bajo una Concepción Emergente. Fuente: (Sampieri et al, 2014)

\section{Resultados}

\subsection{Categoría: Aspectos Didácticos}

4.2 Subcategoría: Diseño instruccional

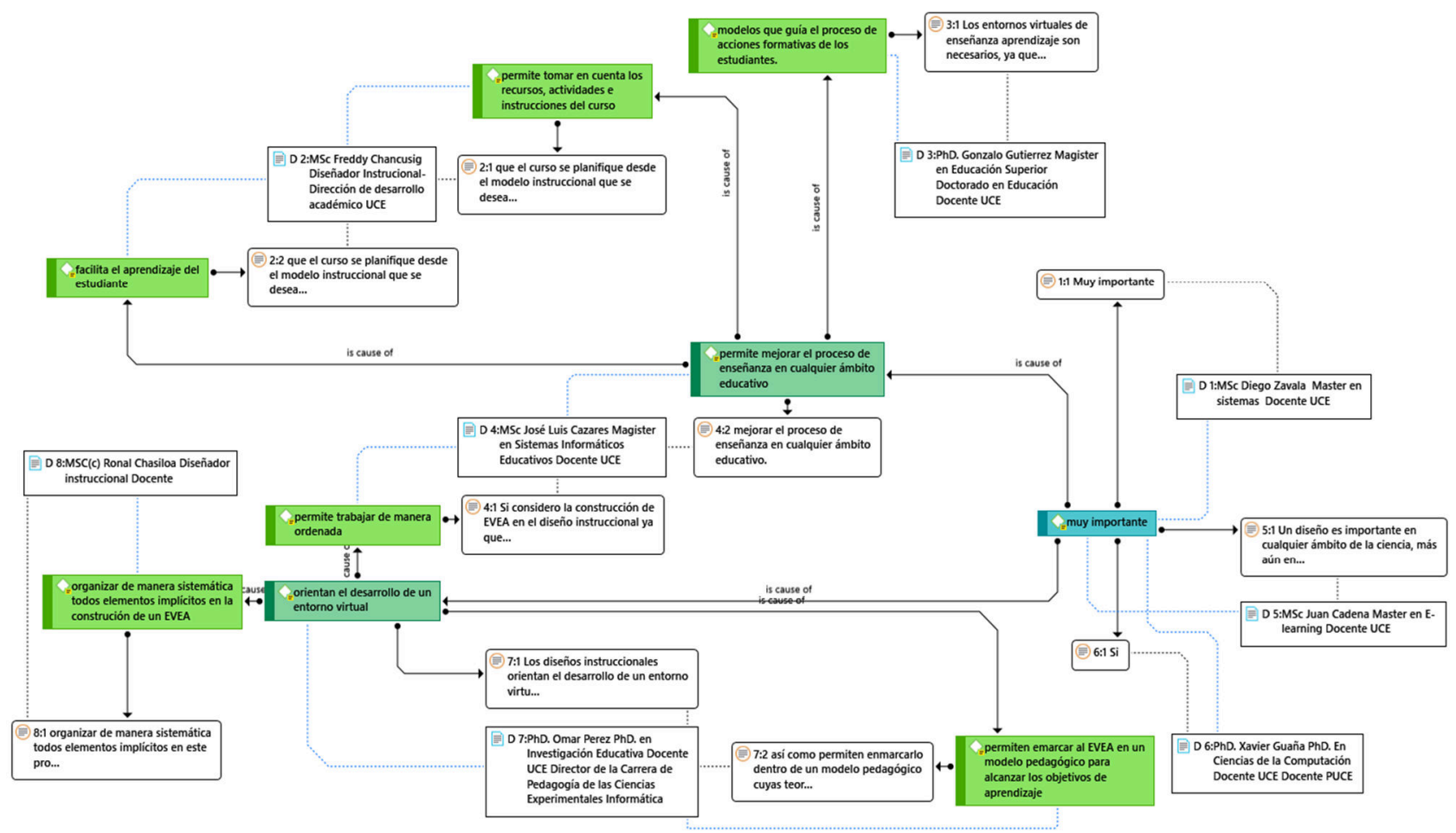

Figura 3. Red conceptual: importancia del diseño instruccional en los EVEA 
Para el desarrollo de EVEA es sumamente importante el uso de un diseño instruccional debido a que su utilización orienta su desarrollo ya que permite organizar todos los elementos implícitos en la construcción de un EVEA tales como los recursos, actividades, instrucciones del curso. Faryaid (2007) asevera que el diseño instruccional permite al docente conceptualizar y diseñar, crear e implementar recursos y actividades que permitirán llevar el proceso de formación de manera adecuada. Además, Belloch (2013) afirma que el diseño instruccional permite la construcción de ambientes de aprendizaje, recursos y actividades claras y efectivas.

En cuanto a la selección de un modelo de diseño instruccional los expertos entrevistados coinciden en el uso del modelo instruccional ADDIE debido a su flexibilidad y a "la fuerza que ha tomado los últimos años debido a que es un modelo genérico" (Castillo, 2009, p.4) de acuerdo a los entrevistados sus fases permiten construir EVEA de calidad ya que toman en cuenta todos los elementos implícitos que formaran parte del EVEA como al grupo de aplicación, contenidos, actividades, características tecnológicas, estrategias de aprendizaje, procesos de evaluación y estrategias de seguimiento para determinar si han alcanzado los resultados de aprendizaje planteados.

\subsection{Subcategoría: Diseño de actividades educativas virtuales}

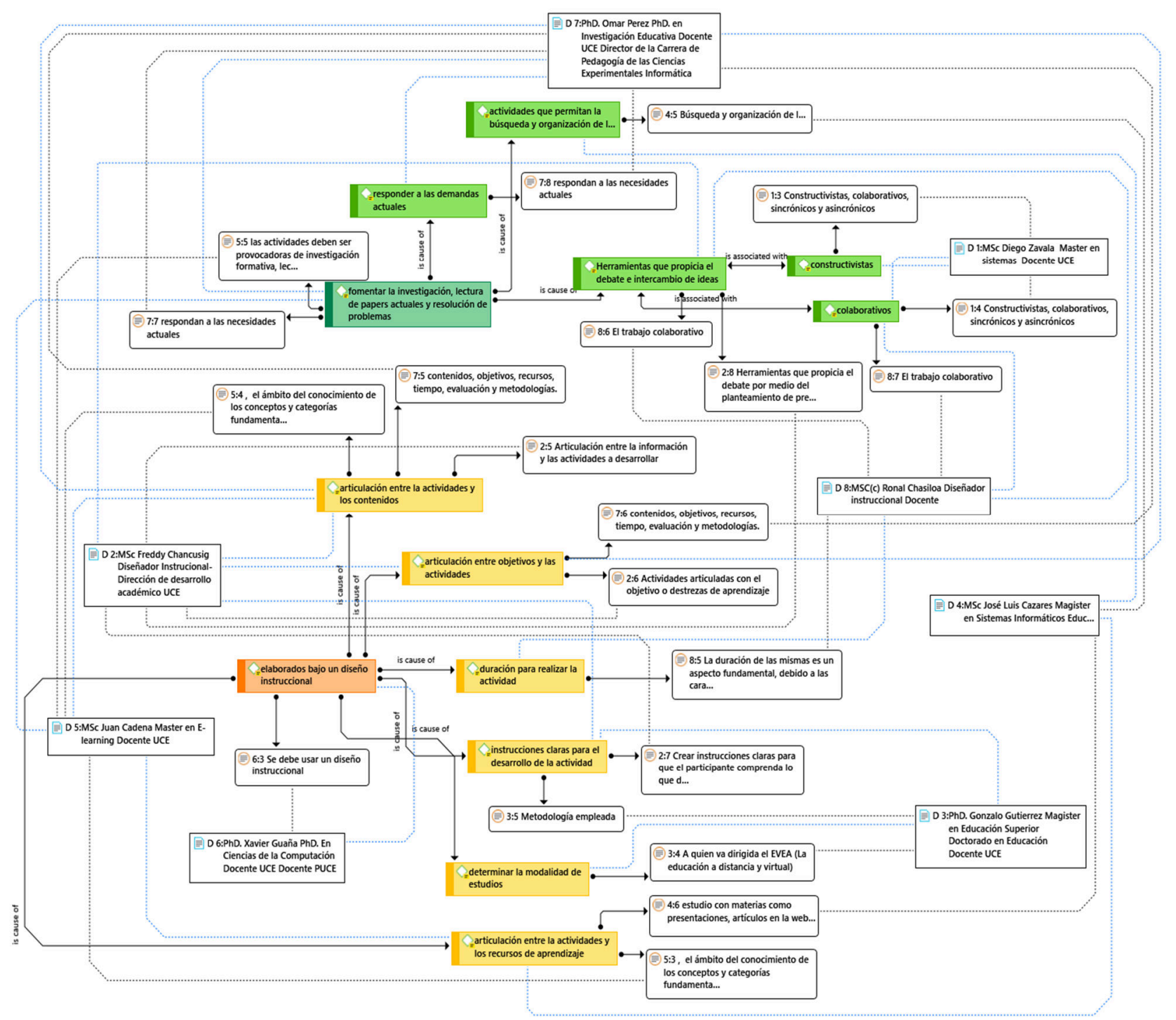

Figura 4. Red conceptual: Criterios didácticos para el diseño de actividades en EVEA.

Licencia Creative Commons Atribución 4.0 Internacional (CC BY 4.0)

Revista Cátedra, 5(1), pp. 80-105, enero-junio 2022. e-ISSN: 2631-2875

https://doi.org/10.29166/catedra.v5i1.3447 
Para el diseño de actividades los entrevistados coinciden en que debe existir una articulación entre los contenidos, objetivos, recursos y la actividad, así como la duración de la actividad y las instrucciones para su realización, además de fomentar el intercambio de ideas, el debate, la investigación, la lectura y la resolución de problemas. Cabero y Román (2006) fortalecen este planteamiento ya que aseveran que los aspectos más importantes para el diseño de actividades virtuales son: especificar las instrucciones para realizar la actividad, determinar los límites de realización, determinar de qué forma será enviada, establecer los recursos a utilizar para su realización y determinar los criterios de valoración de la actividad, así mismo el autor menciona que las actividades deben estar orientadas a la resolución de problemas en las que se desenvuelve el estudiantado. En referencia al tipo de actividades virtuales para desarrollar capacidades mentales superiores en el estudiantado se recomienda utilizar trabajos colaborativos (foros, wikis, tallares); y trabajos autónomos (ensayos, tareas, proyectos y organizadores gráficos). Churches (2009) hace referencia al uso de la taxonomía digital de Bloom para seleccionar actividades virtuales de acuerdo a la capacidad que se desee desarrollar en el estudiantado.

\subsection{Subcategoria: Diseño de recursos educativos virtuales.}

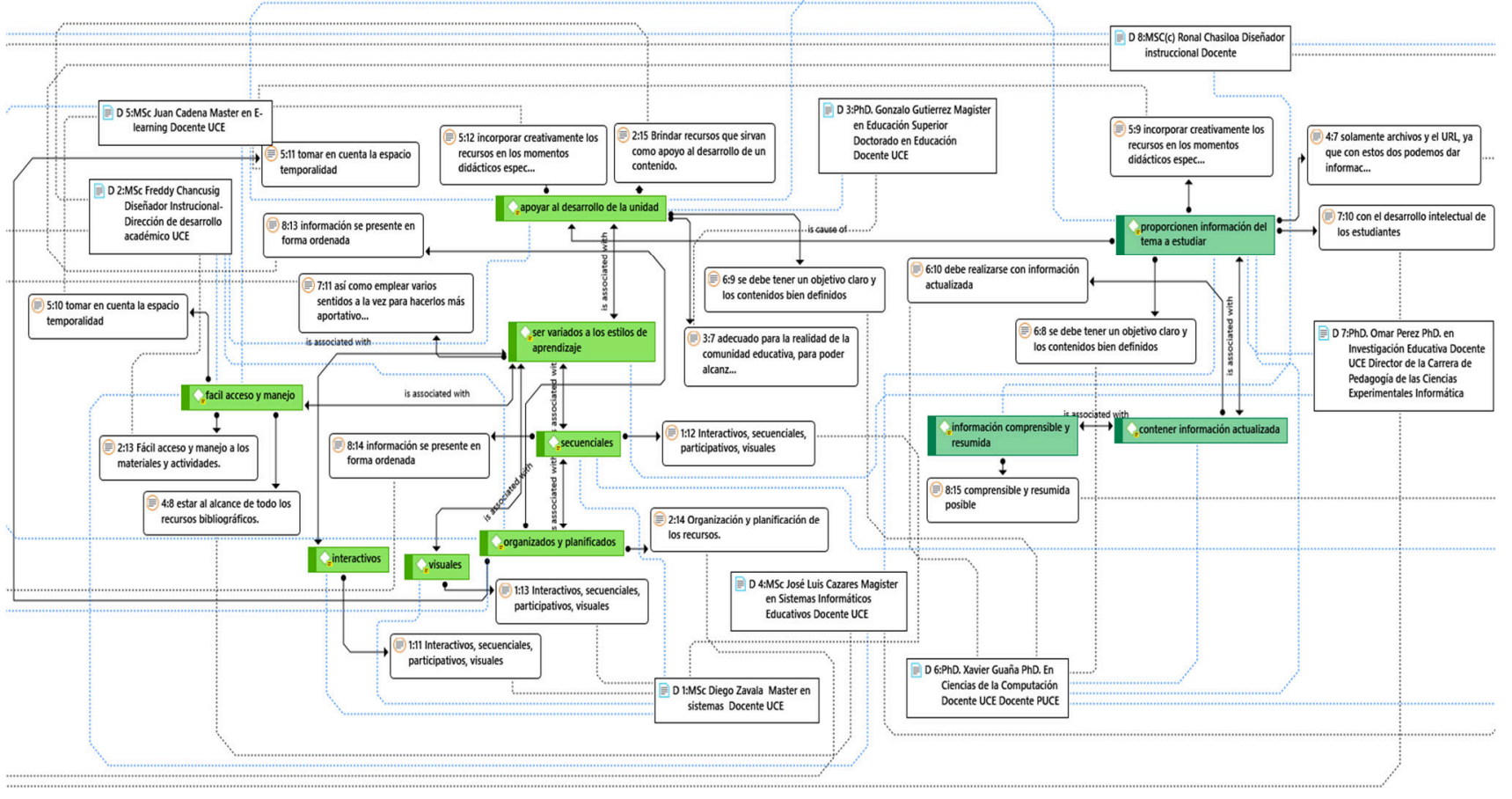

Figura 5. Red conceptual: actividades virtuales para desarrollar capacidades mentales superiores en el estudiantado

Para el diseño de recursos educativos virtuales los entrevistados coinciden que deben cumplir las características siguientes:

a) Ser variados (texto, audio, imágenes, videos) debido a los distintos estilos de aprendizaje del estudiantado.

b) Deben estar elaborados de manera secuencial.

c) Se debe acceder ellos fácilmente.

d) Deben apoyar al desarrollo de la unidad.

e) Deben contener información actualizada, resumida y comprensible de la temática a estudiar.

Entre otras características Zapara (2012) afirma que para desarrollar recursos educativos se deben establecer sus objetivos para delimitar los contenidos que formaran parte de ellos y recomienda apoyar mediante herramientas TIC su presentación. Por último, recomienda 
utilizar los recursos digitales educativos de acuerdo al nivel cognitivo de modo que si se desea explorar conceptos se recomienda el uso de documentos, hipertextos y recursos audiovisuales, y para la consolidación de aprendizajes el uso de simuladores o juegos educativos.

\subsection{Categoría: Aspectos Tecnológicos}

4.6 Subcategoría: Herramientas TIC externas a la plataforma Moodle para el apoyo al aprendizaje.

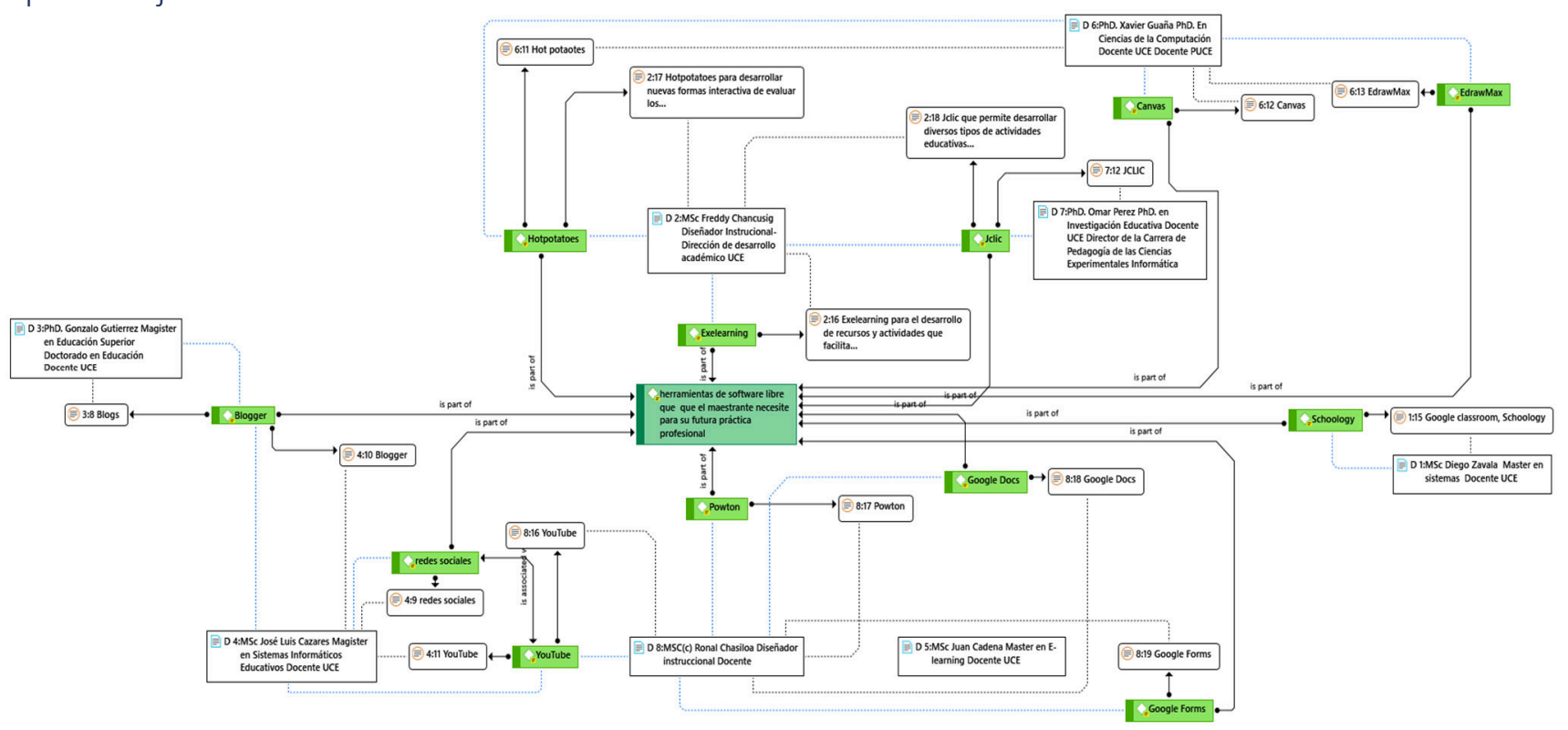

Figura 6. Red conceptual: herramientas TIC externas a la plataforma virtual Moodle para la construcción de actividades y recursos

Como herramientas TIC externas a Moodle que permitan al profesorado construir actividades y recursos, los entrevistados sugieren las herramientas siguientes:

a) Redes sociales como: YouTube y Blogger

b) Herramientas de evaluación como: HotPotatoes y Jclic

c) Herramientas para realizar presentaciones interactivas como: PowToon

d) Herramientas de diseño gráfico de fácil uso como: Canvas

e) Herramientas de diagramación para realizar diagramas de flujo, organigramas, mapas mentales, diagramas de red, etc. como: EdrawMax

Herramientas que faciliten el trabajo colaborativo como: Google Docs y Google Forms 
4.7 Subcategoría: Herramientas TIC propias de la Moodle para el apoyo al aprendizaje.

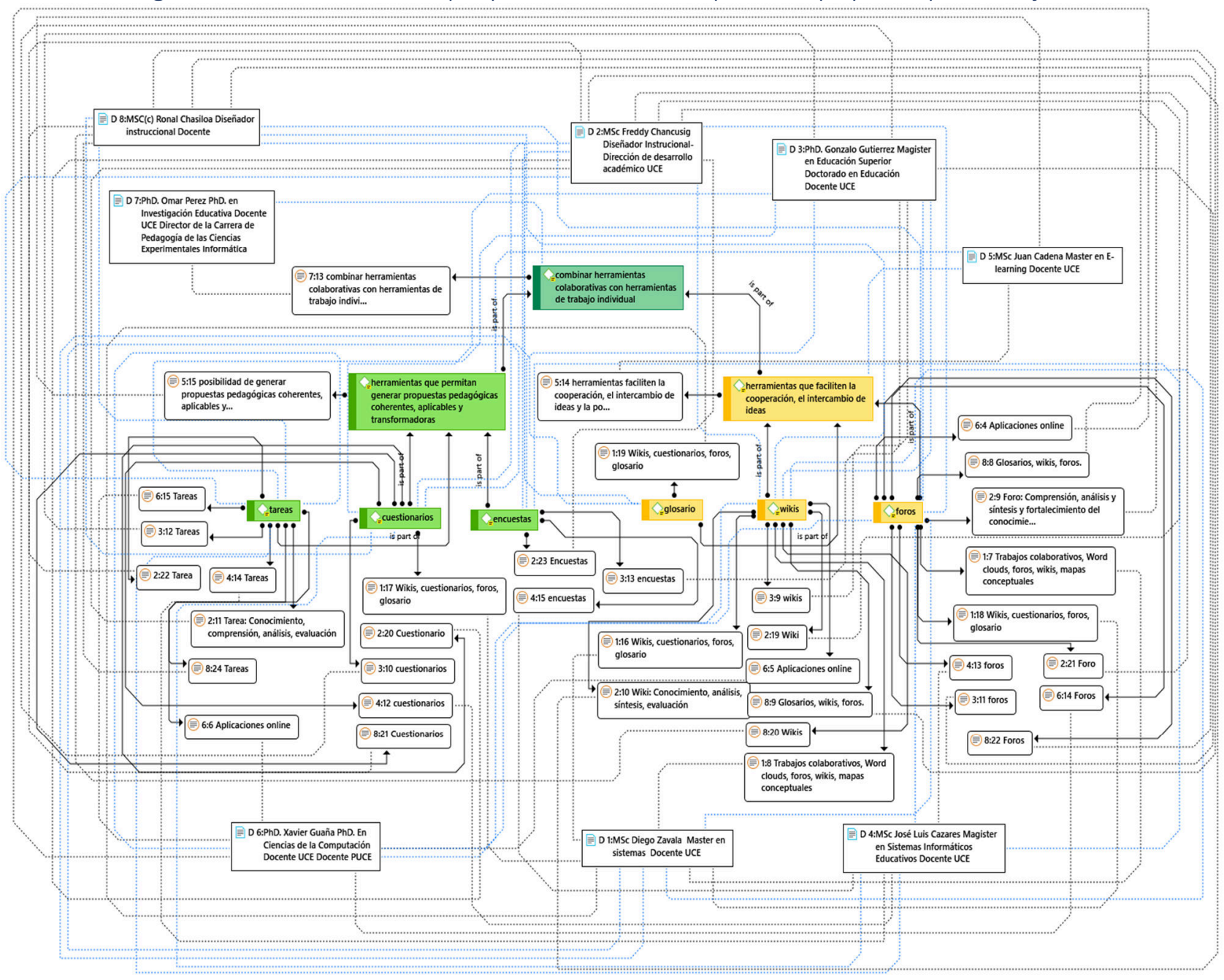

Figura 7. Red conceptual: herramientas TIC propias de la plataforma virtual Moodle para la construcción de actividades y recursos.

Como herramientas TIC propias de la plataforma Moodle más recomendadas para que el profesorado construya actividades y recursos, los entrevistados sugieren utilizar herramientas que permitan desarrollar el trabajo autónomo y colaborativo.

Entre las herramientas para el trabajo autónomo sugiere el uso de la actividad Tareas siempre y cuando estén enfocadas a generar propuestas pedagógicas coherentes, aplicables a la realidad e innovadoras. Finalmente, entre las herramientas que faciliten el trabajo colaborativo e intercambio de ideas recomiendan el uso de: Wikis, Foros y Glosarios. 
4.8 Subcategoría: Interfaz de navegación del EVEA.

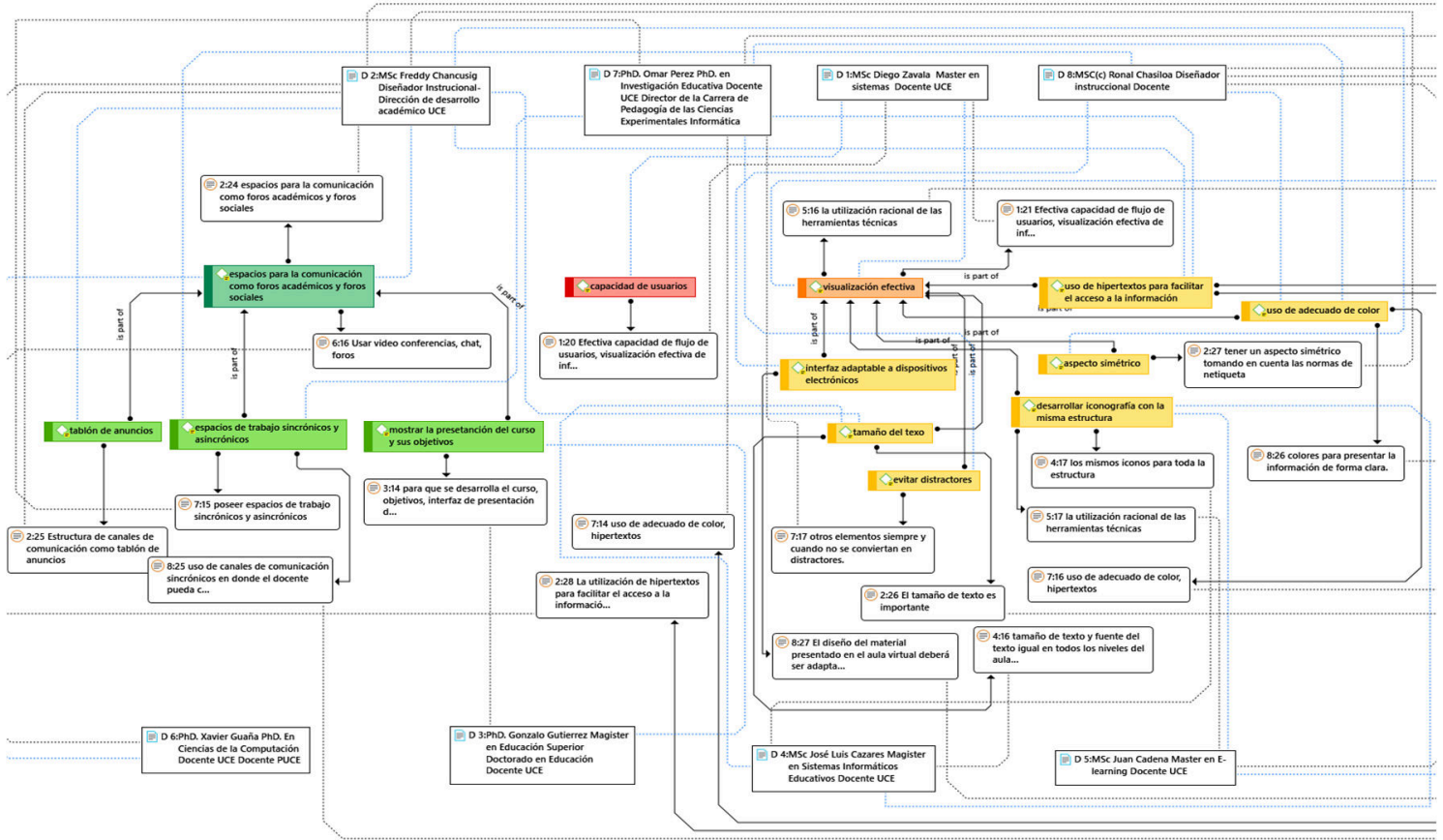

Figura 8. Red conceptual: aspectos técnicos para el diseño de un EVEA.

Entre las consideraciones técnicas que se deben tomar en cuenta para la construcción de un EVEA los entrevistados hacen referencia a:

a) Construcción de espacios para la comunicación académica y social como:

- Tablero de anuncios con información relevante del curso.

- Espacios de trabajo sincrónicos y asincrónicos.

b) Visualización efectiva, es decir:

- Uso de hipertexto para facilitar el acceso a la información.

- Uso adecuado del color y tamaño de texto.

- Desarrollar una iconografía uniforme dentro del curso.

- Evitar distractores.

Rivera (2005) afirma que, en los EVEA, el diseño de interfaz gráfica es fundamental y debe proporcionar al estudiantado elementos necesarios para hacer efectiva la comunicación del contenido, proporcionar el carácter visual necesario y exponer el contenido de acuerdo al tipo de usuarios al que vaya dirigido. Además, González (2004) asevera que el interfaz debe apoyar, ayudar y guiar al usuario por lo que se debe: a) evitar la saturación y colocación innecesaria de elementos; b) organizar la información de manera lógica y jerárquica para acceder a ella fácilmente y localizarla de manera eficaz; c) existir consistencia en todas las secciones de la plataforma, gráficos y tamaño de texto, y; d) en lo que respecta a los recursos y actividades el texto y gráficos que se utilicen deben guardar relación. 


\subsection{Categoría: Aprendizaje en EVEA}

\subsection{Subcategoría: Características del estudiantado adulto (andragogía).}

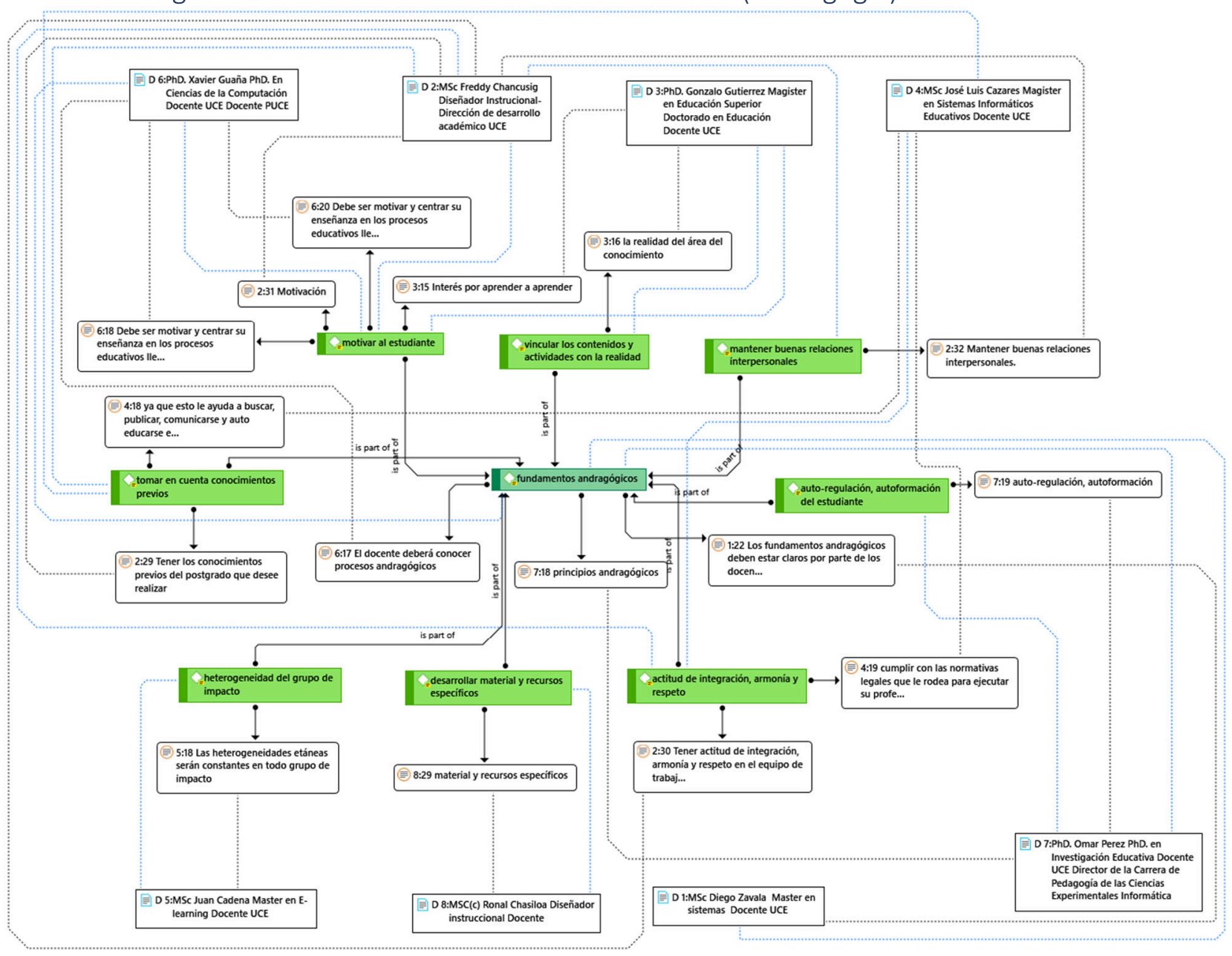

Figura 9. Red conceptual: aspectos andragógicos

Entre los aspectos a considerar en el proceso de aprendizaje del estudiantado los entrevistados hacen referencia a los fundamentos andragógicos y establecen que se debe:

a) Motivar al estudiantado para fomentar la autorregulación y autoformación.

b) Vincular los contenidos y actividades con problemas de la realidad.

c) Desarrollar buenas relaciones interpersonales entre docentes y estudiantes.

d) Tomar en cuenta la heterogeneidad del grupo en cuanto a estilos de aprendizaje, por medio del desarrollo de recursos educativos variados.

Knowles (1984) referente al aprendizaje de personas adultas o andrología respalda las afirmaciones de los entrevistados y asevera lo siguiente:

a) Se deben considerar aspectos tales como concientizar al estudiante la necesidad del aprendizaje, para que por sí mismo, indague los beneficios que pueden obtener al adquirir dicho aprendizaje.

b) Realizar actividades que estén orientadas a hacer frente a problemas de su contexto para despertar su interés y aprender de manera más efectiva.

c) Evitar crear situaciones en las que el estudiante perciba que el docente está imponiendo u ordenando. Knowles y Kolb (2005) afirman que el docente debe respetar las decisiones sobre el nivel de autonomía del estudiantado adulto. 
Considerar estos aspectos permitirán evitar situaciones de resistencia al aprendizaje

d) Considerar la diversidad del estudiantado en lo que respecta a estilos de aprendizaje, necesidades y objetivos.

Además, según los expertos entrevistados y la información contrastada de los autores citados anteriormente el docente debe asumir en el proceso de enseñanza el rol de guía convirtiéndose en un motivador e intermediario del conocimiento, además para una mejor practica del proceso de enseñanza y aplicar las consideraciones mencionadas anteriormente el docente debe ser un experto en la temática de modo que proporcione al estudiantado: a) conocimientos actuales que le permitan fortalecer su práctica profesional; b) material científico apropiado para su análisis, y; c) perfilar al estudiantado a líneas de investigación.

Finalmente, en lo que respecta al rol que debe asumir el estudiantado en el proceso de aprendizaje se menciona que este ser activo participe, crítico y consciente de la necesidad de aprendizaje. Tough (1971) asevera que cuando un estudiante decide aprender por sí mismo, indaga sobre los beneficios que pueden obtener de dicho aprendizaje y las consecuencias negativas de no adquirirlo. Por lo que se debe prestar mucha atención a estos aspectos con el propósito de mantener una actitud de aprendizaje constante y brindar ideas para la solución de problemas.

\subsection{Subcategoría: Estilos de aprendizaje}

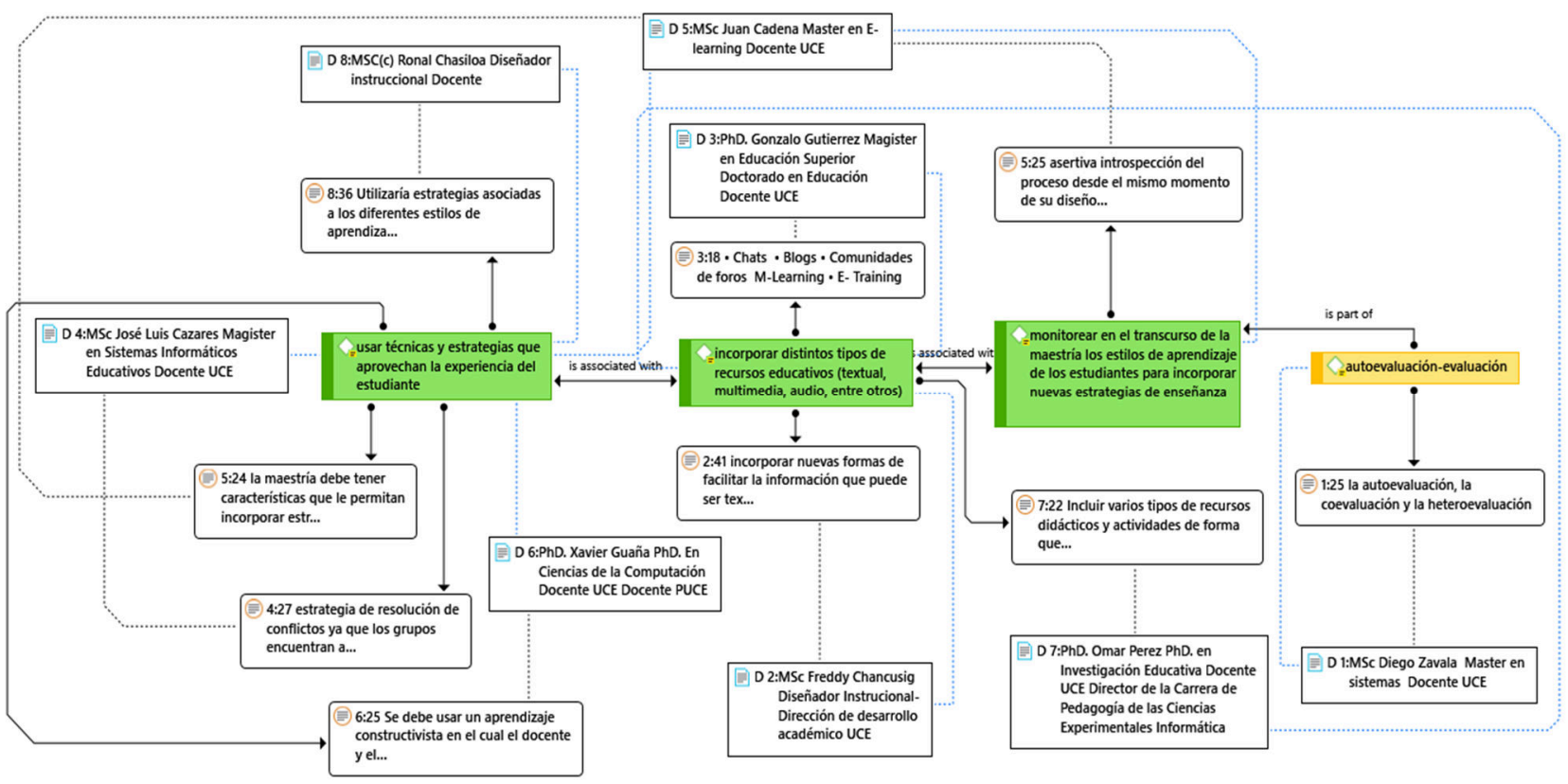

Figura 10. Red conceptual: estrategias para atender los distintos tipos de aprendizaje del estudiantado

Para atender a los distintos tipos de estilos de aprendizaje del estudiantado se sugieren las estrategias siguientes:

a) Incorporar en el EVEA distintos tipos de recursos educativos (textos, imágenes, audios). Bandler y Grinder (1982) aseveran que la información se puede representar de manera visual, auditiva y kinestésica y las personas aprenden en un $40 \%$ de manera visual, en un 30\% de forma auditiva y en un $30 \%$ de forma kinestésica. Por lo que es necesario elaborar recursos que permitan aprender de las formas mencionadas anteriormente. 
b) Usar técnicas y estrategias que aprovechen la experiencia del estudiante. Al respecto Sánchez (2015) menciona que "algunas de las técnicas que aprovechan la experiencia del alumno adulto son los grupos de discusión, los ejercicios de simulación, la resolución de problemas, el estudio de casos, los métodos de laboratorio y las actividades de ayuda entre pares" (p. 97).

Es importante tomar en cuenta estas dos estrategias para el diseño de actividades y recursos dentro del EVEA.

Por último, se hace énfasis a que el docente debe monitorear de manera continua como se desenvuelve el estudiantado en el transcurso del curso para realizar ajustes necesarios en las actividades, recursos o estrategias de enseñanza.

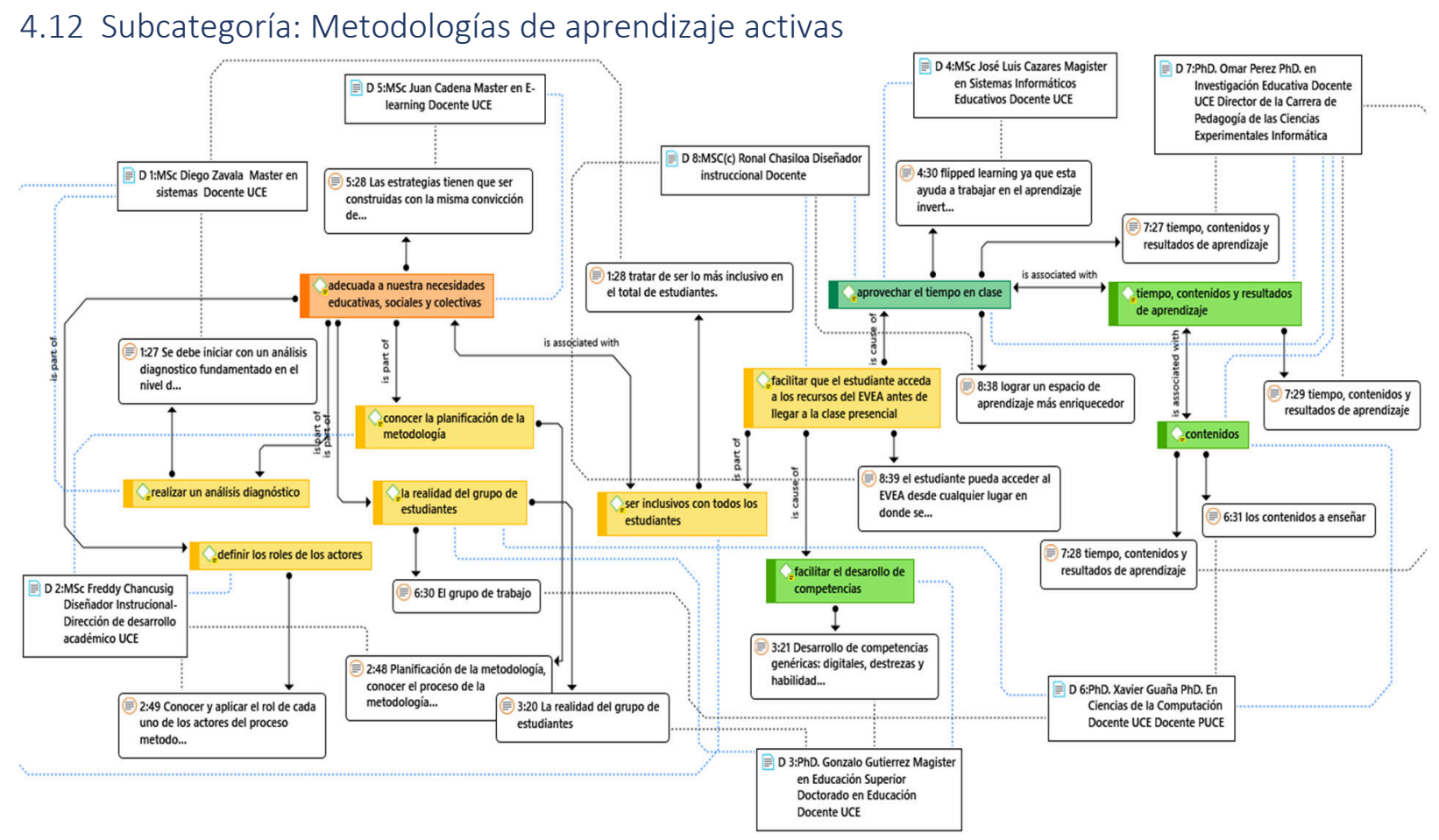

Figura 11. Red conceptual: factores para seleccionar una metodología de aprendizaje activa en EVEA

Por último, en cuanto a los criterios para seleccionar metodologías de aprendizaje activas los entrevistados hacen referencia los ámbitos siguientes:

a) Seleccionar metodologías que se adecuen a las necesidades educativas, sociales y colectivas: considerando el grupo de estudiantes al que se dirige el módulo y siendo inclusivos con los mismos.

b) Aprovechar el tiempo en clase: al respecto se debe facilitar al estudiantado el acceso a los recursos del EVEA para que se analicen antes de llegar a la clase presencial.

Según los criterios de los expertos entrevistados se hace énfasis al uso de TIC con la práctica docente presencial, en este sentido se recomienda el uso del enfoque tecnológico de aprendizaje B-Learning. Bartolomé (2008) fortalece este planteamiento ya que afirma que este enfoque permite aprovechar las ventajas de las TIC y la formación presencial proporcionando:

a) igualdad de oportunidades en el aprendizaje mediante la flexibilidad y adaptabilidad; b) facilitar al estudiante el acceso a recursos y actividades de aprendizaje; c) ofertar al estudiantado mayor variedad de recursos y Licencia Creative Commons Atribución 4.0 Internacional (CC BY 4.0) 
actividades para afrontar diversas situaciones de aprendizaje; y, d) permiten articular las necesidades de los actores implicados en el proceso formativo (p. 18).

Por último, con el propósito de optimizar el tiempo en clases y tomar en cuenta las características del estudiantado adulto analizadas anteriormente, se recomienda el uso de la metodología de aprendizaje activo Flipped Learning, debido a que en esta metodología el estudiantado tiene un rol más protagónico en el aula, ya que realiza el análisis de los contenidos proporcionados por el docente a través de recursos tecnológicos y se aprovecha el tiempo de la clase aplicando los conocimientos adquiridos previamente con la guía del docente, por medio de la solución de problemáticas orientadas a su práctica profesional y solución de situaciones reales. La FLN (2014) asevera que la aplicación de esta metodología permite: a) tomar en cuenta los estilos de aprendizaje de los estudiantes al ofrecer actividades variadas; b) hacer que el estudiante se convierta en el protagonista del aprendizaje debido a que asume la responsabilidad de analizar los recursos, interactuar con el docente y sus compañeros y aportar con ideas para la solución de problemas; c) seleccionar actividades y recursos acordes al objetivo de aprendizaje; $y, d$ ) hacer que el docente asuma el rol de facilitador para brindar retroalimentación, seguimiento y evaluación continua.

\section{Conclusiones}

Para construir un EVEA que permita garantice un aprendizaje de calidad, la investigación llegó a las conclusiones siguientes:

a) Para la construcción de un EVEA es sumamente importante partir de un diseño instruccional con el propósito de conceptualizar, diseñar, organizar crear e implementar las actividades y recursos que formaran parte del EVEA, para alcanzar los logros de aprendizaje.

b) Pese a que existen una gran variedad de modelos de diseños instruccionales se recomienda el uso del modelo ADDIE debido a que es una metodología didáctica virtual a nivel universitario acorde para la plataforma MOODLE, se ajusta en cualquier ámbito educativo y sus fases toman en cuenta todos los elementos implícitos que formaran parte del EVEA como el estudiantado al que se dirige el curso, características tecnológicas, contenidos, actividades, estrategias de aprendizaje, procesos de evaluación y estrategias de seguimiento para determinar si han alcanzado los resultados de aprendizaje planteados.

c) Las actividades que forman parte de EVEA deben guardar relación con los objetivos y contenido del módulo y/o asignatura, además deben estar enfocadas a fomentar el debate, intercambio de ideas, la investigación y resolución de problemas del ámbito profesional en el que se desenvuelve el estudiantado. Para su diseño se debe: a) proporcionar instrucciones claras para su realización; b) establecer el tiempo para su realización; c) proporcionar recursos adicionales para su realización; y, c) dar a conocer los criterios de valoración de la actividad.

d) En referencia al tipo de actividades que formaran parte de un EVEA se recomienda el uso de trabajos colaborativos (foros, wikis, tallares) y trabajos autónomos (ensayos, tareas, proyectos) apoyándose en el uso de la taxonomía digital de Bloom la cual menciona que tipo de actividad puede desarrollar según la capacidad que se desee desarrollar en el estudiantado y el nivel de complejidad.

e) Los recursos educativos virtuales deben contener información actualizada y comprensible para apoyar al desarrollo de la unidad, además deben ser variados para atender a los distintos tipos de estilos de aprendizaje de los estudiantes se recomienda el uso de texto, audios, imágenes, videos, etc. y se debe brindar todas las facilidades para que el estudiante acceda a ellos acorde a los estilos de aprendizaje. 
f) Se sugiere utilizar herramientas TIC que permitan desarrollar el trabajo autónomo y colaborativo, como herramientas para el desarrollo del trabajo autónomo se recomienda el uso de tareas enfocadas a generar propuestas pedagógicas coherentes, aplicables a la realidad e innovadoras, y como herramientas para fortalecer el trabajo colaborativo herramientas que permitan el intercambio de ideas y fomentar el diálogo como: Wikis, Foros y Glosarios.

g) Entre las consideraciones técnicas que se deben tomar para el diseño de un EVEA destacan: a) la creación de un tablero de anuncios con información relevante del módulo; b) el uso de hipertexto para facilitar el acceso a la información; c) uso adecuado del color y tamaño de texto; d) desarrollo de una iconografía uniforme dentro del curso; $y, e)$ evitar el uso innecesario de elemento visuales o recursos en el EVEA.

h) Entre los aspectos a considerar en el proceso de aprendizaje del estudiantado se debe:

- Concientizar al estudiante sobre la necesidad de aprender con el objetivo de que se motive en el proceso de aprendizaje.

- Las actividades que realice el estudiantado deben estar orientadas a la resolución de problemas de su contexto profesional para despertar su interés y aprender de manera más efectiva.

- Se debe tomar en cuenta la autonomía y experiencia del estudiantado en este sentido el docente debe evitar situaciones en las que el estudiante sienta que el docente está imponiendo u ordenando, para no causar resistencia al aprendizaje.

- Tomar en cuenta la heterogeneidad del grupo en cuanto a estilos de aprendizaje.

i) En cuanto a los roles del docente y el estudiantado:

- El docente debe asumir el rol de guía en el proceso de enseñanza convirtiéndose en un motivador e intermediario del conocimiento. Además, debe ser experto en la temática para brindar al estudiantado: a) conocimientos actuales que le permitan fortalecer su práctica profesional; b) contenidos actuales; $y, c)$ perfilar al estudiantado a líneas de investigación.

- El rol del estudiantado en el proceso de aprendizaje debe ser activo, participe, crítico y consciente de la necesidad de aprendizaje brindando ideas para la solución de problemas.

j) Para atender a los distintos tipos de estilos de aprendizaje del estudiantado se deben incorporar en el EVEA distintos tipos de recursos educativos, además de utilizar actividades que aprovechen la experiencia del estudiante como grupos de discusión, los ejercicios de simulación, la resolución de problemas, el estudio de casos, etc.

k) Para la selección de metodologías de aprendizaje activas que forman parte del EVEA se debe:

- Seleccionar metodologías que se adecuen a las necesidades educativas, sociales y colectivas.

- Considerar al grupo de estudiantes al que se dirige el módulo.

- Ser inclusivos con todos los estudiantes para atender a un mundo diverso.

- Seleccionar metodologías y enfoques que permitan aprovechar el tiempo en clase.

- Fortalecer el proceso de enseñanza aprendizaje con herramientas TIC.

- Facilitar al estudiantado el acceso a los contenidos, recurso y actividades. 


\section{Bibliografía}

Banco Mundial (BM, 2017). Momento decisivo: La educación superior en América Latina y el Caribe. Recuperado de https://openknowledge.worldbank.org/bitstream/handle/10986/26489/211014 ovSP.pdf

Bandler, R., y Grinder, J. (1982). Frogs into princess: Neuro linguistic programming. Royal Victorian Institute for the Blind Tertiary Resource Service.

Bartolomé, A. (2008). Entornos de aprendizaje mixto en la educación superior. Revista Iberoamericana de Educación a Distancia, 11(1), 15-51.

Belloch, C. (2010). Entornos virtuales de aprendizaje. Recuperado de https://www.uv.es/bellochc/pedagogia/EVA3.pdf.

Belloch, C. (2013). Diseño instruccional. Valencia, España: Unidad de Tecnología Educativa. Valencia, España: Universidad de Valencia. Recuperado de http://cmapspublic.ihmc.us/rid=1MXBYRSF8-1Y2JTP7-RM/EVA4.pdf

Cabero, J. y Román, P. (2006). E-actividades. Un referente básico para la formación en internet. Sevilla, España: MAD, S. L. Recuperado de http://cmap.javeriana.edu.co/servlet/SBReadResourceServlet?rid=12672913934 $\underline{41107978700814570}$

Castillo, J. (2009). Los tres escenarios de un objeto de aprendizaje. Revista Iberoamericana de Educación. 50(1), 50-55. ISSN 1681-5653.

Crispín, B. (2011). Aprendizaje autónomo: orientaciones para la docencia. México: Universidad Iberoamericana, AC. Recuperado de: http://biblioteca.clacso.edu.ar/Mexico/dcsyp-uia/20170517031227/pdf 671.pdf

Colina, M., y Gutiérrez, M. (2013). Aplicación de un entorno virtual de aprendizaje para el desarrollo de competencias en la unidad curricular completación de pozos. REDHECS, 16(9), 67-89.

Consejo de Educación Superior. (2020). Oferta vigente del Sistema de Educación Superior.

Recuperado de http://appcmi.ces.gob.ec/oferta vigente/

Flipped Learning Network. (2014). ¿Qué es el 'aprendizaje invertido' o Flipped Learning? Recuperado de http://flippedlearning.org/domain/46

Gunawardena, Ch., Lowe, C. y Anderson, T. (1997). Analysis of a global online debate and the development of an interaction analysis model for examining social construction of knowledge in computer conferencing. Journal of Educational Computing Research, $17(4), 395-429$.

Internet World Stats (2020). World internet Users and Population Stats. Recuperado de http://www.internetworldstats.com/stats.htm

Johnson, D. y Johnson, R. (1999). Aprender juntos y solos. Buenos Aires, Argentina: Aiqué. 
Knowles, M. S. (1975) Self-directed learning: a guide for learners and teachers. New York, EU.: Association Press.

Knowles, M. S. (1978) Adult Learner. A neglected species. (2th ed.) Houston, EU.: Gulf Publishing Company.

Knowles, M. S. (1980). The modern practice of adult education: From pedagogy to andragogy. Englewoods Cliff, NJ: Cambridge Adult Education.

Knowles, M. S. (1984). Andragogy in Action. Applying modern principles of adult education. San Francisco, EU.: Jossey Bass.

Knowles, M. S. (1989). The Making of an Adult Educator. An autobiographical Journey. San Francisco: Jossey-Bass.

Knowles, M. S. (1990). Adult Learner. A neglected species. (4th ed.) Houston, EU.: Gulf Publishing Company.

Monereo, C y Castello, M (1997). Las estrategias de aprendizaje. Cómo incorporarlas a la práctica educativa. Barcelona, España: Edebé.

Monje-Álvarez, C. A. (2011). Metodología de la investigación cuantitativa y cualitativa. Neiva-Colombia: Universidad Surcolombiana. Recuperado de https://www.uv.mx/rmipe/files/2017/02/Guia-didactica-metodologia-de-lainvestigacion.pdf\#page $=96 \&$ zoom $=100,148,728$

Online Buisnnes Scohol (2015). Imperio de E-Learning para 2019. Recuperado de https://www.elmundo.es/sociedad/

Organización para la Cooperación y el Desarrollo Económicos (2015). E-learning in Higher Education in Latin America. París, Francia: Development Centre Studies, OECD. Recuperado de http://dx.doi.org/10.1787/9789264209992-en

Paz-Florio, M. (2015). Programa Virtual de Formación Docente 2015: "Expandir y enriquecer la enseñanza y el aprendizaje a través de las TIC". Buenos Aires-Argentina: Centro de Innovaciones en Tecnología y Pedagogía (Citep). Universidad de Buenos Aires. Recuperado de http://citep.rec.uba.ar/entornos-virtuales-de-ensenanza-yaprendizaje-evea-nivel-1-

2/\#: :text=Los\%20Entornos\%20Virtuales\%20de\%20Ense\%C3\%B1anza,organiz adas $\% 20$ en $\% 20$ torno $\% 20$ al\%20aprendizaje

Salinas, J. (2012). Reseña del libro diseño y moderación de entornos virtuales de aprendizaje (eva). Revista de Universidad y Sociedad del Conocimiento (RUSC). 9(1), 194-197.

Salmerón, H., Rodríguez, S., y Gutiérrez, C. (2010). Metodologías que optimizan la comunicación en entornos de aprendizaje virtual. Comunicar, XVII(34),163171.[fecha de Consulta 12 de Junio de 2020]. ISSN: 1134-3478. Recuperado de https://www.redalyc.org/articulo.oa?id=158/15812481019

Sampieri, R. H., Collado, C. F., y Baptista, M. D. (2014). Metodología de la Investigación (6ta. ed.). DF, México: Mc Graw Hill. 
Sánchez, M. (2018, marzo). Origen y evolución de internet y su desarrollo como entorno de interacción social a través de los medios sociales digitales. Revista Contribuciones a las Ciencias Sociales. Recuperado de https://www.eumed.net/rev/cccss/2018/03/medios-sociales-digitales.html

SUMMA (2019). Orientaciones para la Formación Docente y el Trabajo en el aula: Aprendizaje Colaborativo. Recuperado de https://panorama.oei.org.ar/dev2/wpcontent/uploads/2019/05/APRENDIZAJE-COLABORATIVO.pdf

Tesouro, M. y Puiggalí, J. (2004). Evolución y utilización de internet en la educación. PixelBit: Revista de Medios y Educación, (24) 59-67. Recuperado de https://idus.us.es/handle/11441/45584

Zapara, M. (2012). Recursos educativos digitales: conceptos básicos. Programa Integración de Tecnologías a la docencia. Universidad de Antioquia. Recuperado de http://aprendeenlinea.udea.edu.co/boa/contenidos.php/d211b52ee1441a30b59a e008e2d31386/845/estilo/aHR0cDovL2FwcmVuZGVlbmxpbmVhLnVkZWEuZWR 1LmNvL2VzdGlsb3MvYXp1bF9jb3Jwb3JhdGl2by5jc3M=/1/contenido/

\section{Autores}

JORGE SANTAMARIA-MUÑOZ obtuvo su título de Magíster en educación Mención en Gestión del Aprendizaje Mediado por TIC, por la Facultad de Filosofía, Letras y Ciencias de la Educación de la Universidad Central del Ecuador en 2021. Obtuvo el título de Licenciado en Ciencias de la Educación, mención: Informática por la Facultad de Filosofía, Letras y Ciencias de la Educación de la Universidad Central del Ecuador en 2016.

Actualmente se desempeña como administrador de la plataforma virtual educativa para los programas de grado y posgrado, de la Facultad de Filosofía, Letras y Ciencias de la Educación de la Universidad Central del Ecuador, y es parte del equipo tecnológico en la Revista Catedra de la Universidad Central del Ecuador. Además de ser parte de proyectos de Investigación titulados: "Impacto del rendimiento académico del ingreso de los estudiantes a la universidad pública ecuatoriana. Caso Universidad Central del Ecuador" y "Proyecto Etnomatemática" 